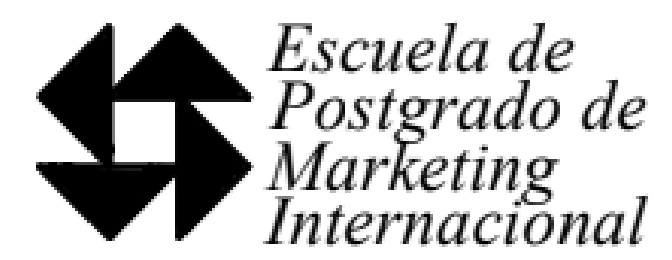

\title{
Plan estratégico de marketing internacional para una comercializadora de frutos secos
}

Trabajo Científico libre para la obtención del grado de

Magister en Marketing Internacional de la

Escuela de Postgrado de Marketing Internacional

Facultad de Ciencias Económicas

- Universidad Nacional de La Plata -

Director de Tesis

Presentado por

Prof. Mg. Enzo Campana

Steven Cerpa Pinto

Beruti 4441, CABA.

Fecha de entrega: 9 de marzo de 2020 
Todos nuestros sueños pueden convertirse en realidad si tenemos el coraje de perseguirlos.

Walt Disney

Antes que nada, agradezco a Dios por permitirme realizar uno de mis anhelados deseos.

Gracias a mi socia, amiga y esposa, por siempre estar ahí para mi, por darme la confianza cuando más me faltaba. A mi familia, que en la distancia siempre me dieron su apoyo.

A este país que me abrió las puertas, llenando mis conocimientos de un eterno valor.

A mi tutor Mg. Enzo Campana, que gracias a sus consejos y sugerencias pude llevar adelante este proyecto.

A la vida, por cruzarme siempre con personas nobles y dispuestas a ayudarme. En especial a Liesel Bischoff por estar siempre ahí en la coordinación de la EPMI resolviendo las dudas que surgen en esta instancia. 


\section{PLAN ESTRATÉGICO DE MARKETING INTERNACIONAL PARA UNA COMERCIALIZADORA DE FRUTOS SECOS}

Índice del contenido

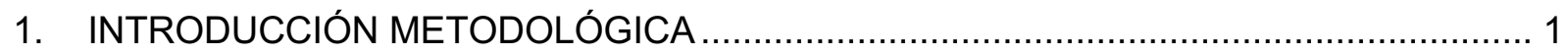

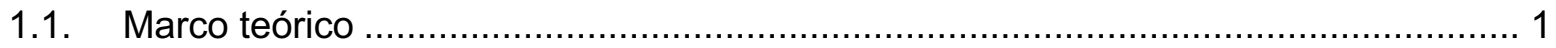

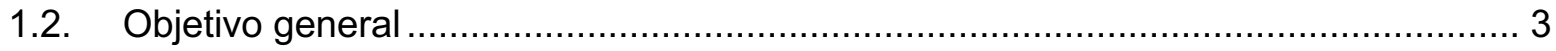

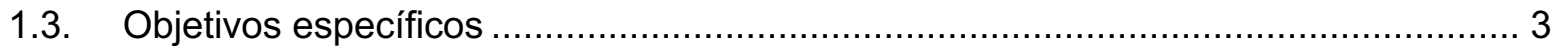

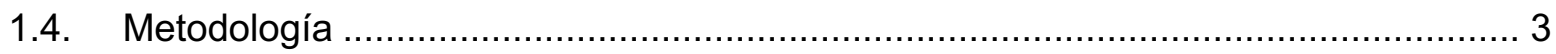

2. ORIENTACIÓN COMERCIAL INTERNACIONAL ..................................................... 5

2.1. Situación actual de consumo de alimentos saludables........................................... 5

2.2. Situación actual del consumo de frutos secos ................................................... 6

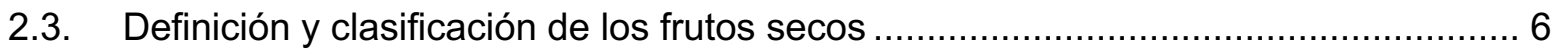

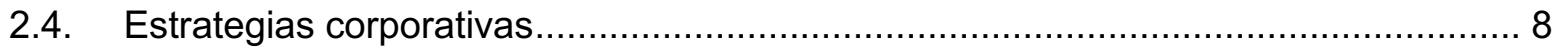

2.4.1. Consideraciones previas para el diseño de una propuesta de misión:................ 8

2.4.2. Consideraciones previas al diseño de una propuesta de visión: ........................ 9

2.4.3. Definición del negocio:............................................................................ 10

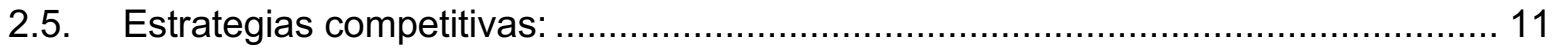

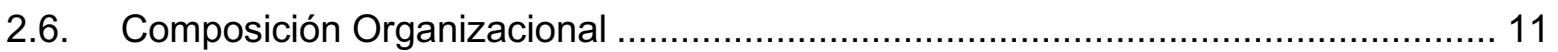

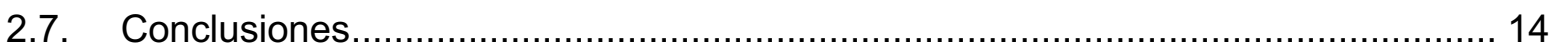

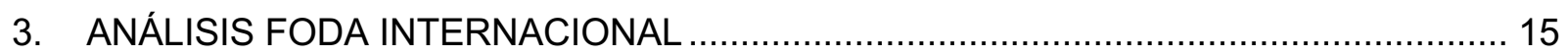

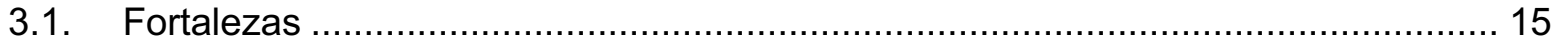

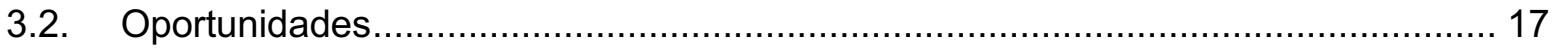

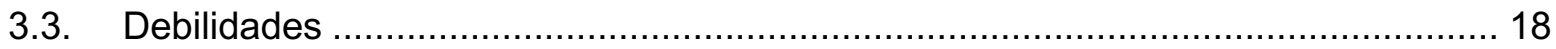




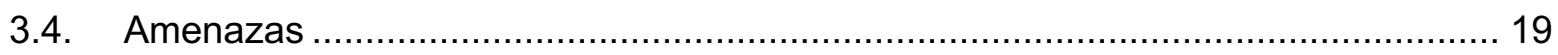

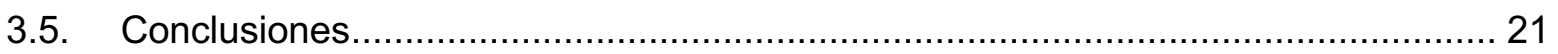

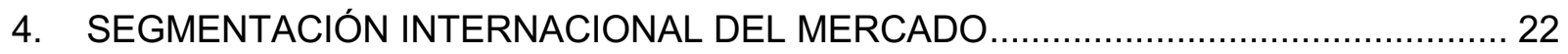

4.1. Características del mercado internacional de frutos secos.................................. 22

4.2. Características principales del mercado de alimentos en Colombia......................... 24

4.3. Características del mercado de los snacks en Colombia ..................................... 25

4.4. Oportunidad comercial entre Argentina y Colombia ………................................ 26

4.5. Conceptualización del mercado colombiano de referencia.................................... 27

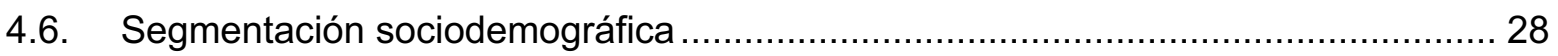

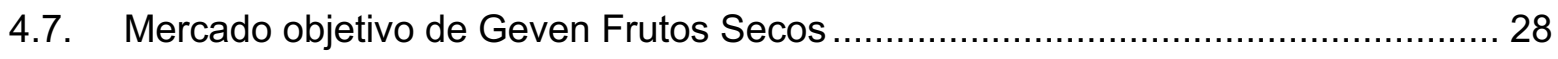

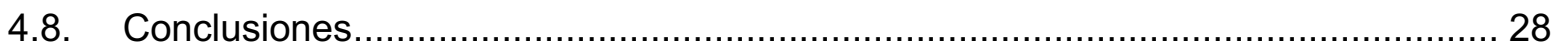

5. OBJETIVOS PARA LA COMERCIALIZACIÓN INTERNACIONAL................................30

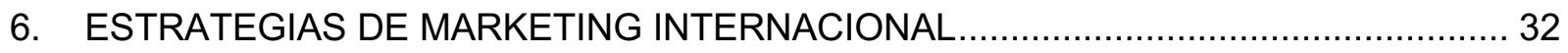

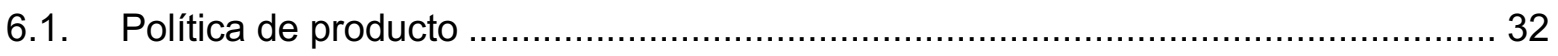

6.1.1. Empacado y fraccionamiento del producto en Colombia................................ 33

6.1.2. Atributos y características del producto ………........................................ 34

6.1.3. Clasificación del producto ...................................................................... 40

6.1.4. Gama y línea de productos ................................................................... 41

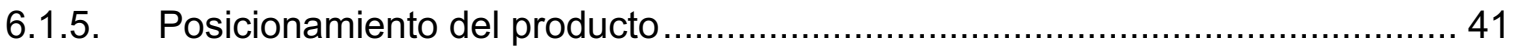

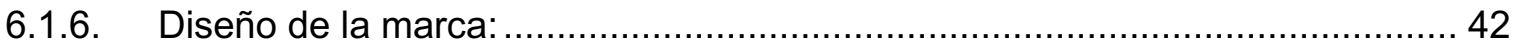

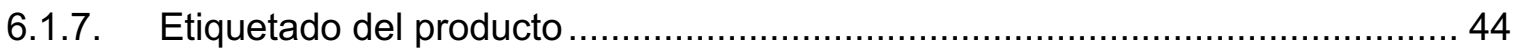

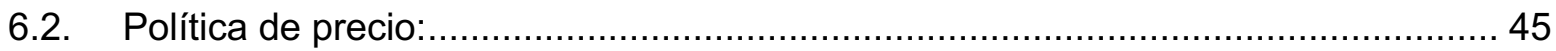

6.2.1. Precio promedio de los principales competidores en Colombia ....................... 45

6.2.2. Objetivo de precio ........................................................................... 47

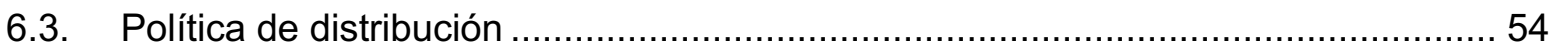

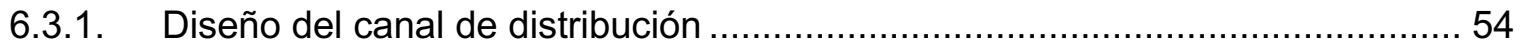

6.3.2. Características del website para la comercialización en Colombia ................... 54 
6.4. Políticas de comunicación................................................................... 55

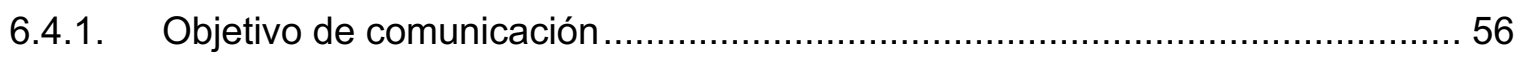

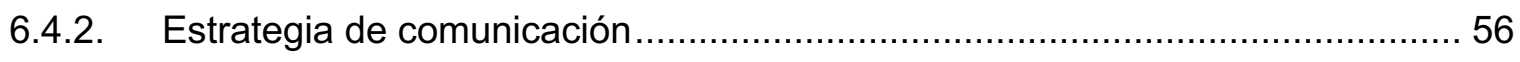

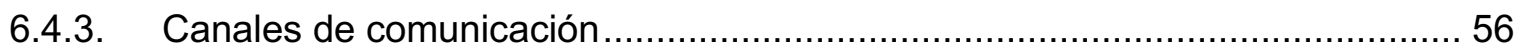

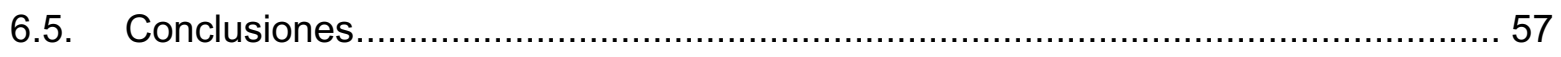

7. VIABILIDAD ECONÓMICA Y FINANCIERA DEL PROYECTO ................................ 58

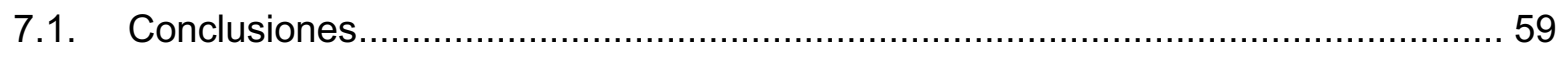

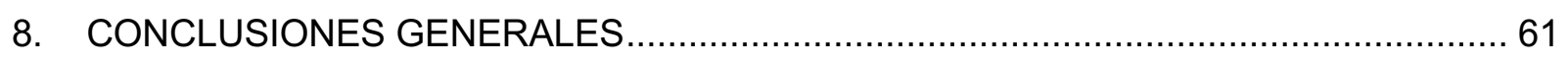

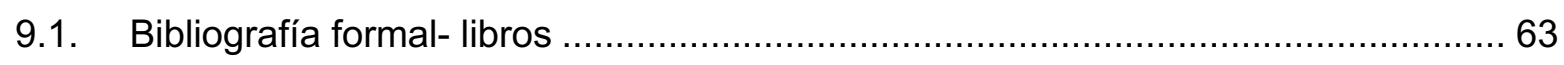

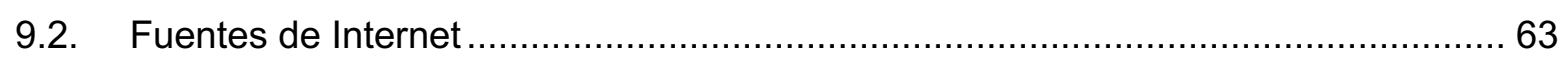


Índice de tablas

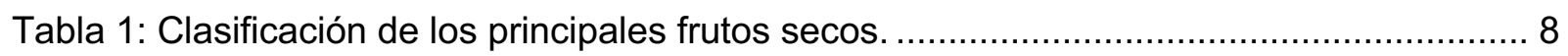

Tabla 2: Información nutricional nuez nogal por 100 gramos............................................ 36

Tabla 3: Información nutricional nuez pecán por 100 gramos............................................ 38

Tabla 4: Información nutricional pistacho por 100 gramos.............................................. 40

Tabla 5: Precio de los principales competidores de nuez de nogal. .................................. 46

Tabla 6: Precio principales competidores de nuez de pecán.............................................. 46

Tabla 7: Precio principales competidores de pistacho. ...................................................... 47

Tabla 8: Información básica de los productos a exportar................................................. 49

Tabla 9: Información básica del embarque. …………….......................................... 50

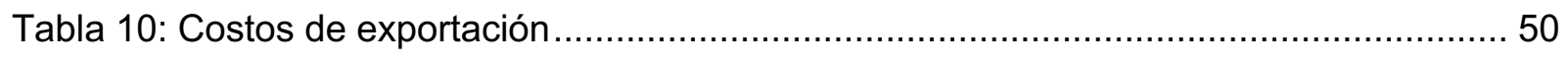

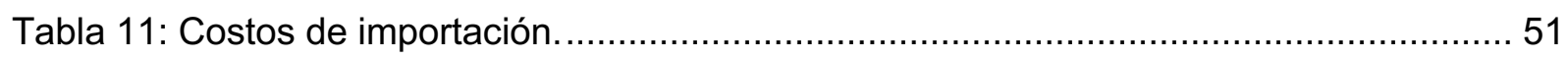

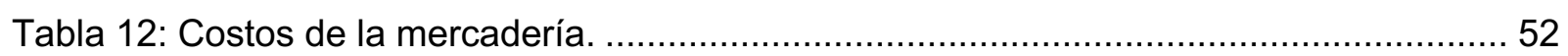

Tabla 13: Cálculo de precios de las nueces de nogal.................................................. 52

Tabla 14: Cálculo de precio de las nueces de pecán....................................................... 53

Tabla 15: Cálculo de precio de los pistachos.................................................................. 53

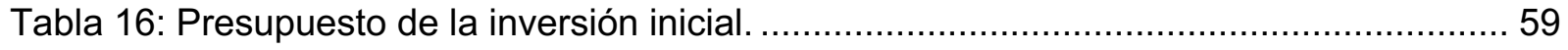

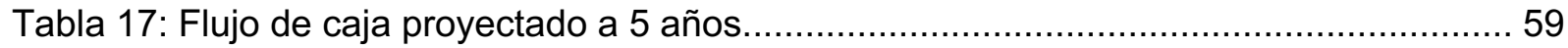


Índice de esquemas

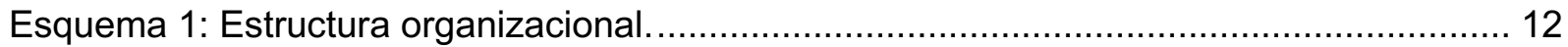

Esquema 2: Producción de los frutos secos en porcentajes por países 2018/2019 ............ 23

Esquema 3: Consumo estimado de frutos secos en toneladas métricas por países, 2017 ... 24

Esquema 4: Exportaciones de Argentina a Colombia ................................................ 26

Esquema 5: Exportaciones Argentina de frutas secas o procesadas a Colombia ................ 27

Esquema 6: Diseño del canal de distribución............................................................... 54 
Índice de ilustraciones

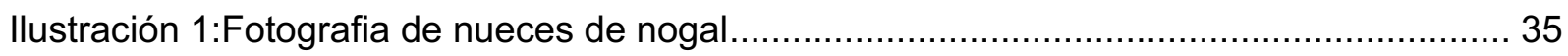

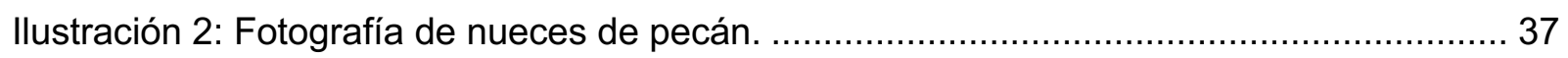

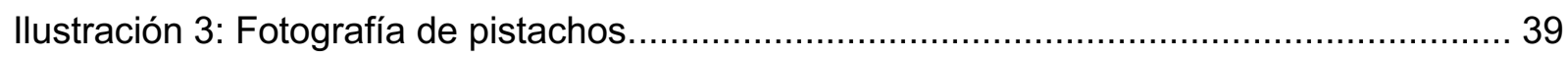

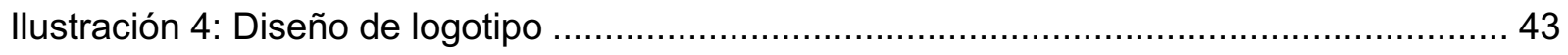

llustración 5: Muestra de diseño de empaques......................................................... 44 


\section{INTRODUCCIÓN METODOLÓGICA}

\subsection{Marco teórico}

El mercado global actual se caracteriza por ser competitivo y cambiante, cualquier empresa con interés en incursionar en países extranjeros desde su creación, debe como mínimo, seguir una hoja de ruta que le permita planificar, controlar y medir las estrategias elegidas para el nuevo camino a transitar. La concepción de un proyecto comercial con miras al mercado internacional comprende una serie de pasos decisivos que permitan prever el mejor resultado posible.

Lambin ${ }^{1}$ afirma que la gestión del marketing estratégico se sitúa en el medio-largo plazo; su función es precisar la misión de la empresa, definir sus objetivos, elaborar una estrategia de desarrollo y velar por mantener una estructura equilibrada de la cartera de productos. Esto se constituye como el punto de partida de un proyecto de comercialización internacional.

Continuando con Lambin ${ }^{2}$ la reflexión estratégica de la empresa debe materializarse en un programa de acción que precise los objetivos y los medios a poner en marcha en el marco de la estrategia de desarrollo elegida. De acuerdo a lo anterior, la planificación anticipada es parte fundamental de un plan estratégico de marketing.

Según Hoyos ${ }^{3}$ un plan de marketing es un documento que relaciona los objetivos de una organización en el área comercial con sus recursos, es la bitácora mediante la cual la empresa establece qué objetivos comerciales quiere alcanzar y qué debe hacer para alcanzar dichos objetivos, es decir, la estrategia de marketing. Por otro lado, García ${ }^{4}$

\footnotetext{
${ }^{1}$ Lambin, J. J. (1995) Marketing Estratégico (c.1, pp.8) Madrid: Mc Graw Hill

2 Lambin, J. J. (1995) Marketing Estratégico (c.14, pp.569) Madrid: Mc Graw Hill

${ }^{3}$ Hoyos, R. (2013) Plan de marketing: diseño, implementación y control. (c. 1, pp.21) Bogotá: Ecoe Ediciones

${ }^{4}$ García, M. S (2014) Plan e informes de marketing internacional. (c.1, pp.1) España: IC Editorial
} 
establece que el plan de marketing se adecúa a las decisiones y actuaciones que aseguren la supervivencia de la empresa a largo plazo, porque suele relacionarse más con el ámbito estratégico que con el operativo.

En consecuencia a lo anterior, el plan de marketing se convierte en la base fundamental para la consecución de los objetivos comerciales, permite tomar decisiones que repercutan en un mayor progreso para la compañía, a partir del previo conocimiento del mercado, sus necesidades y tendencias de consumo.

De acuerdo con Carpintero ${ }^{5}$ el plan de marketing internacional es en el punto de partida de cualquier empresa que quiere comercializar sus productos en mercados exteriores, por lo que este plan ha de seguir unas pautas relativamente distintas al plan de marketing diseñado para el mercado nacional. Por su parte García $^{6}$ afirma que el plan de marketing internacional debe ser una parte más del plan de marketing general, por lo que debe ser doblemente coherente: primero con el plan de marketing de la empresa y segundo con el plan estratégico global de la compañía.

Otra pieza importante enmarcada dentro de las acciones del marketing global de la empresa es el plan de marketing digital, que según Hernández ${ }^{7}$ es un documento que recoge la situación, los objetivos, estrategias, tácticas y acciones desarrolladas en el entorno online. Paralelamente a la concepción del plan de marketing general de la compañía, es imprescindible tomar en cuenta el entorno online, que hoy día ha ganado gran protagonismo.

Carpintero ${ }^{8}$ afirma que el contenido del plan de marketing internacional comprende:

- Análisis de la situación

- Determinación de objetivos

- Elaboración y selección de estrategias

- Plan de acción

\footnotetext{
${ }^{5}$ Carpintero, L. (2014) Plan e informes de marketing internacional. España: (c.1, pp.5) Ediciones Paraninfo S.A.

${ }^{6}$ García, M. S (2014) Plan e informes de marketing internacional. (c.1, pp.6) España: IC Editorial

${ }^{7}$ Hernández, C. (2017) Manual. Fundamentos del plan de marketing en internet. (c.2, pp.22) Madrid: Editorial CEP

${ }^{8}$ Carpintero, L. (2014) Plan e informes de marketing internacional. España: (c.1, pp.9) Ediciones Paraninfo S.A.
} 
- Establecimiento de presupuesto

- Métodos de control

Adicional a lo anterior, Lambin ${ }^{9}$ establece que el plan estratégico de marketing tiene esencialmente por objetivo expresar de una forma clara y sistemática, las opciones elegidas por la empresa, para asegurar su desarrollo a medio y largo plazo.

A modo de conclusión, un plan de marketing estratégico internacional constituye el esquema donde reposan las acciones de marketing que pretende llevar a cabo la nueva empresa en el nuevo mercado extranjero.

\subsection{Objetivo general}

- Establecer los lineamientos que permitan planear las estrategias de Marketing Internacional para la comercialización de frutos secos.

\subsection{Objetivos específicos}

- Definir la orientación comercial internacional del proyecto.

- Declarar el análisis FODA internacional.

- Exponer la segmentación internacional del mercado.

- Definir los objetivos para la comercialización internacional de frutos secos.

- Determinar las estrategias de marketing internacional.

- Exponer la viabilidad económica y financiera del proyecto internacional.

\subsection{Metodología}

La delimitación temporal para este proyecto de tesis es actual, porque se desarrollará un plan estratégico de marketing internacional para una comercializadora de frutos secos con miras a ejecutarse en un futuro cercano.

${ }^{9}$ Lambin, J. J. (1995) Marketing Estratégico (c.14, pp.569) Madrid: Mc Graw Hill 
La delimitación geográfica del proyecto de tesis es internacional, dado que se trata de un plan estratégico de marketing internacional que se llevará a cabo fuera de Argentina.

Para la ejecución de este proyecto de tesis se utilizarán datos cuantitativos que serán de gran utilidad para conocer las características del mercado destino donde se pretende llevar a cabo el plan estratégico de marketing.

Se utilizarán fuentes secundarias que se obtendrán mediante consulta de estadísticas y data cuantitativa relacionada al sector de la comercialización de frutos secos en el mercado destino, esta información servirá para la toma de decisiones clave a lo largo del desarrollo del plan estratégico.

A modo de conclusión, se llevará a cabo una investigación de tipo exploratoria, pues se pretende recopilar y organizar la información necesaria para crear un plan estratégico de marketing a nivel internacional para una comercializadora de frutos secos. 


\section{ORIENTACIÓN COMERCIAL INTERNACIONAL}

A lo largo de este capítulo se definirá la orientación comercial internacional del proyecto, partiendo de la creación de una nueva empresa argentina con miras a exportar y comercializar frutos secos en Colombia.

2.1. Situación actual de consumo de alimentos saludables

Los hábitos alimenticios en el mundo están cambiando, las personas están preocupándose cada vez más por consumir alimentos saludables que les permitan llevar un estilo de vida sano.

Internet y las redes sociales, sin duda son precursores de estos cambios, ya que hoy en día es mucho más sencillo acceder a información útil sobre el valor nutricional de los ingredientes que se utilizan para las preparaciones diarias.

Dentro de las recomendaciones de la Organización Mundial de la Salud (OMS) ${ }^{10}$ para llevar una dieta sana y equilibrada, está la ingesta diaria de al menos un $30 \%$ de grasas no saturadas, presentes en pescados, aguacates, frutos secos, y en los aceites de girasol, soja, canola y oliva.

En Colombia ${ }^{11}$ los consumidores son cada vez más conscientes de la relación entre sus hábitos de consumo y su salud como consecuencia de la confluencia de varios factores: mayor esfuerzo de la regulación por parte del Estado, consumidores más informados y mayor oferta en el punto de venta del producto con características saludables.

\footnotetext{
${ }^{10}$ Organización Mundial de la Salud. (OMS). Recuperado de: https://www.who.int/es/news-room/fact-sheets/detail/healthy-diet

${ }^{11}$ Nielsen. Recuperado de: https://www.nielsen.com/co/es/insights/article/2018/comida-saludable-todo-estaservido-para-crecer/
} 
En sintonía con lo anterior, la tendencia hacia una alimentación más saludable y consciente ha llegado a todos los rincones del mundo, siendo Colombia un mercado potencial para la comercialización de este tipo de productos.

\subsection{Situación actual del consumo de frutos secos}

Según datos del Consejo Internacional de Frutos Secos $(\mathrm{INC})^{12}$ el consumo de nueces (almendras, nueces, castañas de cajú, pistachos, avellanas, nueces pecanas, macadamias, piñones y nueces de Brasil) ha venido aumentando en los últimos 10 años, siendo el incremento más significativo en las economías de bajos ingresos, donde el consumo pasó de $34.000^{\mathrm{TM}}$ en 2007 a más de $220.000^{\mathrm{TM}}$ en 2017.

La mayoría de los frutos secos consumidos en Colombia provienen del mercado exterior, Chile y Estados Unidos son los principales proveedores. El consumo pér cápita es de $2 \mathrm{~kg}$ anuales. Por el momento, no se registran importaciones de frutos secos desde Argentina.

\subsection{Definición y clasificación de los frutos secos}

Se denominan frutos $\operatorname{secos}^{13}$ a los que en su estado natural de maduración presentan un contenido de humedad que permite conservarlos sin necesidad de someterlos a un tratamiento especial. Poseen un endocarpio más o menos lignificado, y la parte comestible es la semilla.

Los frutos secos son un grupo de alimentos muy energéticos y completos que aportan vitaminas, minerales, proteínas y ácidos grasos insaturados para la alimentación de las personas, además son ricos en fibras y antioxidantes lo cual ayuda a evitar enfermedades degenerativas y desacelerar el envejecimiento. ${ }^{14}$

\footnotetext{
12 Consejo Internacional de Frutos Secos (INC). Recuperado de: https://www.nutfruit.org/industry/technicalresources?category=statistical-yearbooks

${ }^{13}$ Código Alimentario Argentino, Capítulo XI. Recuperado de https://www.argentina.gob.ar/anmat/codigoalimentario

${ }^{14}$ Alimentos argentinos. Recuperado de:

http://www.alimentosargentinos.gob.ar/HomeAlimentos/Nutricion/fichaspdf/Ficha 54 Frutos Secos.pdf
} 
Las grasas que predominan en los frutos secos, son ácidos grasos insaturados. Ácidos grasos poliinsaturados (omega 3 y omega 6) se encuentran principalmente en nueces, mientras que los monoinsaturados (omega 9) se encuentran en mayor cantidad en almendras, avellanas y pistachos. Estos alimentos por ser de origen natural como todos los de su categoría, no contienen colesterol.

Los frutos secos, a pesar de que contienen un $20 \%$ de proteína y son muy recomendados para ayudar a la reducción del colesterol evitando la reducción de sufrir problemas cardiovasculares, no son calificados como reemplazantes de los productos de proteína origen animal.

A continuación, una tabla con la clasificación de los principales frutos secos según la Organización de las Naciones Unidas para la Alimentación y la Agricultura (FAO):

\begin{tabular}{|l|l|}
\hline Nombre común & Nombre taxonómico \\
\hline Anacardos & Anacardium occidentale L. Anacardiaceae \\
\hline Pistachos & Pistacia vea Anacardiaceae \\
\hline Semilla de girasol & Helianthus annuus, Compositae \\
\hline Avellanas & Corylus avellana, Corylaceae \\
\hline Castañas & Castanea dentata, Fagaceae \\
\hline Nueces pecanas & Carya illinoinensis, Juglandaceae \\
\hline Nueces persas & Juglans regia, Juglandaceae \\
\hline Nuez de Brasil & Bertholletia excelsa, Lecythidaceae \\
\hline Cacahuates & Arachis hypogea, Leguminosae \\
\hline Nueces de macadamia & Macadamia integrifolia, Proteaceae \\
\hline
\end{tabular}




\begin{tabular}{|l|l|}
\hline Almendras & Prunus dulcis, Rosaceae \\
\hline Cocos & Cocos nucifera, Palmae \\
\hline
\end{tabular}

Tabla 1: Clasificación de los principales frutos secos.

Fuente: Organización de las Naciones Unidas para la Alimentación y la Agricultura. FAO ${ }^{15}$

Las especies elegidas para iniciar la exportación y posterior comercialización desde Argentina a Colombia son: nueces de nogal, nueces de pecán y pistachos, ya que hay abastecimiento suficiente en Argentina para el mercado interno e internacional, lo que se evidenció gracias al estudio expuesto en la tesis "Proyecto para la exportación de frutos secos" realizada por la maestranda Gheraldine Mancilla.

\subsection{Estrategias corporativas}

Las estrategias corporativas comprenden las decisiones que definen la visión, la misión, el negocio y la estrategia competitiva de la empresa ${ }^{16}$, estos serán los cimientos para definir la orientación comercial internacional de este proyecto.

El nombre designado para la comercializadora internacional de frutos secos es Geven Frutos Secos.

2.4.1. Consideraciones previas para el diseño de una propuesta de misión:

- Es una empresa nueva y familiar con la firme intención de llevar un producto de calidad y nutritivo, siendo una comercializadora de frutos secos que ofrece una amplia variedad y opciones saludables. Desde su inicio, Geven Frutos Secos es una empresa creativa e innovadora que le facilita a sus clientes la obtención de productos saludables de la más alta calidad.

\footnotetext{
${ }^{15}$ Organización de las Naciones Unidas para la Alimentación y la Agricultura. FAO. Recuperado de: http://www.fao.org/3/a-v8929e.pdf

${ }^{16}$ Carpintero, L. (2014) Plan e informes de marketing internacional. España: (c.1, pp.26) Ediciones Paraninfo S.A.
} 
- La misión de Geven Frutos Secos es ser la comercializadora de alimentos ricos y nutritivos logrando el liderazgo en el mercado destino de alimentos saludables con la mejor calidad.

- El área clave para este proyecto es la calidad de los productos, ya que serán exportados de Argentina a Colombia, convirtiéndose en una comercializadora internacional con suficiente abastecimiento de productos, teniendo siempre respuesta para la demanda y ofreciendo una elección saludable y nutritiva para todo tipo de clientes.

- El valor agregado que se da a los productos exportados a Colombia, es que provienen de Argentina, siendo cosechados y cultivados en las provincias de San Juan y Entre Ríos, regiones con producciones de alta calidad. lo que se evidenció gracias al estudio expuesto en la tesis "Proyecto para la exportación de frutos secos" realizada por la maestranda Gheraldine Mancilla.

- Es una empresa flexible e innovadora, capaz de adaptarse a los nuevos retos que presenta el mercado de consumo internacional. Las habilidades que transfiere son: confianza, calidad y actualidad.

- Los valores y la cultura corporativa van mucho más allá de sólo ofrecer un snack a los clientes, es también la forma en que se quiere transmitir que comer sano está de moda y que es posible consumir alimentos ricos y saludables. Los frutos secos son snacks bajos en calorías y altos en grasas buenas.

Misión:

Promover e inspirar un estilo de vida sano que contribuya a mejorar la calidad de vida de nuestros clientes.

2.4.2. Consideraciones previas al diseño de una propuesta de visión: 
- Geven Frutos Secos espera ser una de las empresas jóvenes con mayor proyección internacional, conservando siempre -desde el inicio- la disciplina, la calidad y precios accesibles. Quiere convertirse en la primera opción para el cliente al momento de elegir una alternativa saludable en frutos secos.

- La filosofía gira en torno a ofrecer productos de alta calidad que prioricen el bienestar de los clientes promoviendo un estilo de vida saludable.

- Los valores que caracterizan a Geven Frutos Secos son la perseverancia, la honestidad y la entrega. La prioridad será la satisfacción de los clientes.

Visión:

Ser la empresa internacional líder en frutos secos con productos accesibles de alta calidad.

\subsubsection{Definición del negocio:}

- La necesidad a satisfacer es la de un consumo saludable y nutritivo, a través de snacks -soluciones rápidas para calmar el hambre- como alternativa que brinda muchos beneficios a la salud.

- Los clientes de Geven Frutos Secos son personas activas, que se preocupan por mantener una dieta balanceada, hacer ejercicio con frecuencia y descansar lo suficiente. El rango etario parte de los 18 años y acompaña a los consumidores a lo largo de toda su vida.

- Los productos que comercializa la empresa son frutos secos cultivados y cosechados en Argentina, país con potencial de crecimiento en este sector. En un principio se comenzará con nueces de nogal, nueces de pecán y pistachos, esperando en un futuro ampliar la oferta de productos. La idea es facilitar a los mayoristas la compra vía online a través de un website por medio de e-commerce. 
2.5. Estrategias competitivas:

- El nicho de mercado de Geven Frutos Secos está enfocado en personas que mantienen un estilo de vida saludable, preocupándose por sus alimentos, eligiendo siempre opciones naturales.

- Los productos que comercializa son frutos secos naturales empacados en cajas de 50 unidades con presentaciones de 100 gramos por unidad, directamente exportados de Argentina.

- Geven Frutos Secos es una empresa exportadora pionera en incursionar al mercado colombiano con un portafolio de frutos secos, ya que, dado el poco portafolio de productos en este país, son escasas las empresas dedicadas a este mercado

- La propuesta inicial es comercializar los productos de Geven Frutos Secos a través de una plataforma electrónica donde se muestre información detallada del producto, en la que -a su vez- los mayoristas puedan realizar sus pedidos.

\subsection{Composición Organizacional}

Para la ejecución de este proyecto, primero se debe conformar una Sociedad Comercial para permitir la operación de la empresa Geven Frutos Secos en Argentina.

Posteriormente, la empresa deberá registrarse como PYME (pequeña y mediana empresa) ante la Administración General de Ingresos Públicos AFIP ${ }^{17}$ (Administración Federal de Ingresos Públicos). Los requisitos para este trámite son: tener CUIT (Clave Única de Identificación Tributaria), tener Clave Fiscal 2 o superior, en el Régimen General y estar adherido a la plataforma TAD (Trámites A Distancia).

El registro se puede hacer online y permite acceder a los siguientes beneficios:

\footnotetext{
${ }^{17}$ Ministerio de Desarrollo Productivo. Registrarse como PYME. Recuperado de: https://www.argentina.gob.ar/produccion/registrarse-como-pyme
} 
- Pago de IVA a 90 días

- Incentivos fiscales para PYMEs que invierten

- Alícuota de contribuciones patronales en Seguridad Fiscal

- Exención del impuesto al retiro y efectivo para micro y pequeñas empresas

- Compensación del impuesto de cheque en el pago de las ganancias

- Simplificación en la solicitud de certificado de no retención de IVA

- Incremento salarial por Decreto 14 de 2020

- Exención de la comisión bancaria por depósito de efectivo

- Eliminación del impuesto a la ganancia mínima presunta

- Reducción de retenciones para microempresas de comercio

- Prórroga para medidas cautelares.

La estructura organizacional para Geven Frutos Secos es la siguiente:

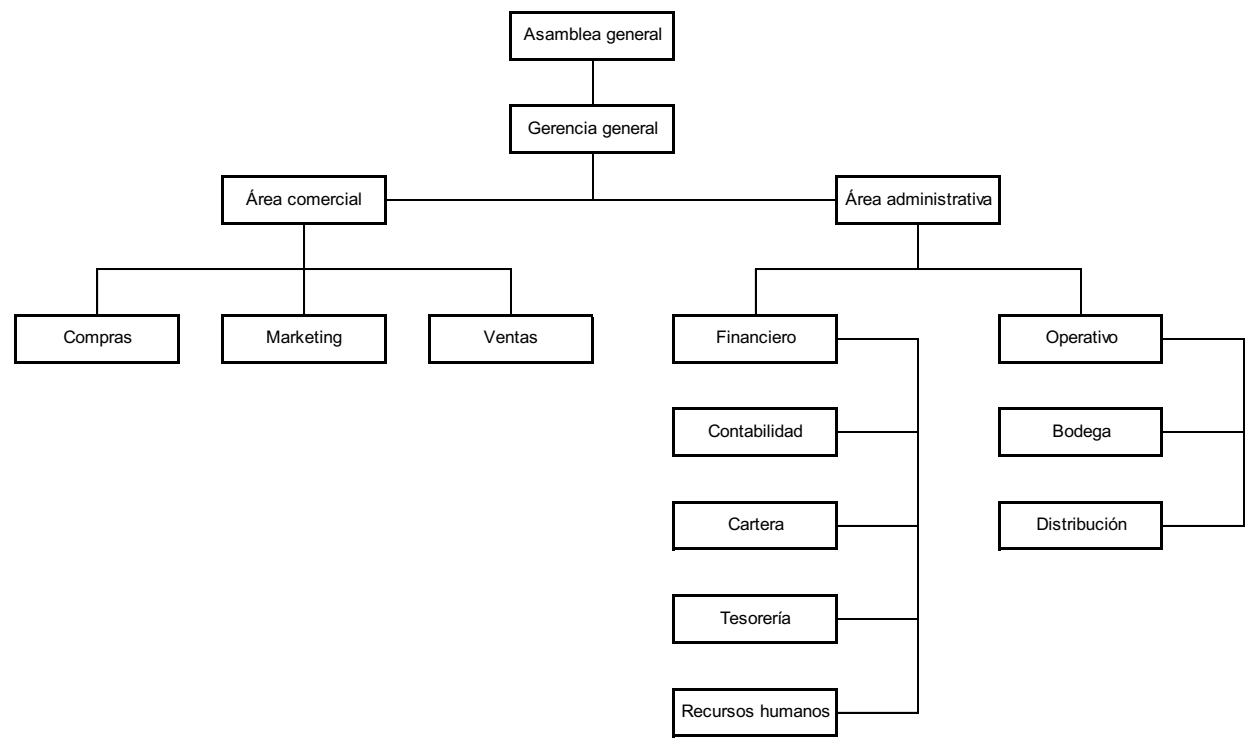

Esquema 1: Estructura organizacional.

Fuente: elaboración propia. 
Por tratarse de una empresa familiar nueva y pequeña, la estructura orgánica es muy sencilla, centrada principalmente en la actividad inicial programada. A continuación, se define brevemente el organigrama:

- Asamblea general: conformada por la totalidad de los socios activos de la empresa. Es la responsable de hacer el direccionamiento general (objeto social, estatutos) de elegir al gerente general y de aprobar -o improbar- los estados financieros.

- Gerencia general: es la responsable de la planeación y de la toma de decisiones para el logro del objeto social de la empresa. Se erige como el líder, debe mantener la motivación y la armonía para que la empresa genere rentabilidad.

Desde allí se desprenden dos áreas, una comercial y una administrativa.

- El área comercial se ocupa de desarrollar el objeto social de la empresa, mientas que el área administrativa provee todo el soporte económico, financiero y logístico para que el objeto social se desarrolle sin contratiempos.

Dentro del área comercial, se distinguen tres procesos fundamentales, las compras, el marketing y las ventas.

- Las compras comprenden la solicitud de cotizaciones de productos a potenciales proveedores mayoristas, la definición de la calidad de producto requerida y la cantidad de producto necesario.

- El marketing incluye los estudios de mercadeo y la publicidad necesaria para colocar el producto de forma efectiva en el mercado.

- El proceso de ventas significa la concreción de los procesos de marketing, representados en negocios efectivos.

Por su parte, el área administrativa comprende los procesos operativo y financiero. 
- El proceso operativo contempla el manejo real de los productos en su tránsito al interior de la empresa (bodegaje o almacenamiento y distribución).

- El proceso financiero incluye todo el movimiento de recursos de la empresa, desde la vinculación de personal, hasta la recuperación de cartera (contabilidad, tesorería).

Es importante mencionar que todos los procesos se conectan en alguna medida, comportándose como un engranaje que tiene como fin primordial el logro del objeto social de la empresa.

También cabe mencionar que, inicialmente, habrá -dentro del organigrama- personas que se encarguen de más de una función o proceso, mientras la empresa logra consolidar sus ventas y fortalecerse para proveer todos los cargos definidos. Así, al inicio, será el gerente quien -con la colaboración de un asistente multifuncional- desarrolle todas las tareas, con el apoyo de un proceso de marketing tercerizado y de una asesoría contable a tiempo parcial, como en general nacen todas las empresas comerciales.

\subsection{Conclusiones}

En el desarrollo de este capítulo se identificó la producción y consumo actual de los frutos secos en el mundo y en el mercado destino, Colombia, con cifras que demuestran la tendencia de crecimiento en esta categoría de producto.

Se investigaron los requisitos y trámites necesarios en Argentina para el establecimiento de la empresa y su posterior ingreso al mercado internacional.

Gracias a la información obtenida, se establecieron los cimientos sobre los cuales se apoyará la orientación comercial internacional de este proyecto. 


\section{ANÁLISIS FODA INTERNACIONAL}

En este capítulo se expondrá el análisis de la situación tanto interna como externa de la empresa Geven Frutos Secos, con el fin de conocer el punto de partida actual para el nuevo mercado a incursionar.

El análisis FODA ${ }^{18}$ abarca el estudio de los distintos factores que interactúan en el proceso de intercambio y de aquellos que conforman el entorno de la operación, con el objetivo de detectar las oportunidades y amenazas de la empresa. Mediante este análisis también se desvelan las fortalezas y debilidades propias de la compañía.

Geven Frutos Secos incursiona en el mercado colombiano como una marca nueva en el segmento de los snacks, es necesario evaluar las posibilidades y posibles riesgos que enfrenta el negocio en su etapa inicial de comercialización internacional.

La auditoría de los escenarios internos y externo de Geven Frutos Secos permite llegar a los siguientes puntos:

\subsection{Fortalezas}

Las fortalezas van a servir de fundamentos a la estrategia básica escogida y determinan el tipo de ventaja competitiva que se posee en relación a los competidores prioritarios ${ }^{19}$.

Es clave tener un panorama claro de las fortalezas de una nueva empresa, ya que esto servirá en parte para potenciar o desarrollar las estrategias de marketing necesarias al llevar a cabo una conquista exitosa de un nuevo mercado.

18 García, M. S (2014) Plan e informes de marketing internacional. (c.4, pp.26) España: IC Editorial

${ }^{19}$ Lambin, J. J. (1995) Marketing Estratégico. (c.14, pp.583) Madrid: Mc Graw Hill 
Las fortalezas de Geven Frutos Secos son:

- Una nueva propuesta especializada en frutos secos en Colombia, ya que no existen muchas empresas que comercialicen estos productos.

- Distribución de los productos a supermercados, gimnasios, quioscos y tiendas naturales, todo con el fin de facilitarle la compra al cliente.

- Frutos secos de alta calidad, con numerosos beneficios para la salud, exportados desde Argentina.

- Reducción de costos, ya que no habrá intermediarios en la comercialización del producto. Geven Frutos Secos exportará la mercadería y la venderá a distribuidores mayoristas.

- Productos que van de la mano con la demanda de los consumidores actuales colombianos, quienes se preocupan por comer alimentos saludables y naturales.

- Creación de una marca coherente y fuerte que transmita un producto de calidad, con características premium.

- El uso de medios promocionales $100 \%$ online, que demuestran tener un mayor éxito en la comunicación en mercados jóvenes.

- Son productos que se pueden conservar con calidad óptima de 2 a 4 semanas en la alacena, pero si son llevados a congelar pueden durar hasta un año, solo basta con sacarlos del empaque e ingerirlos directamente, o si se prefiere tostarlos. Esto representa una ventaja frente a otros productos del mismo segmento con dificultad de almacenamiento. 


\subsection{Oportunidades}

Las oportunidades comprenden las coyunturas externas que podrían apoyar el logro de las metas definidas, por lo que una vez identificadas, se deben aprovechar. ${ }^{20}$

Es requisito tener claros todos los aspectos del entorno que eventualmente podrían convertirse en puntos a favor de la comercializadora, esto con el fin de conocer de antemano el mercado y poder prever el recibimiento del producto.

Las oportunidades de Geven Frutos Secos son:

- En Colombia ${ }^{21}$ la población actualmente es de 48,2 millones de habitantes, con un porcentaje de $51,2 \%$ mujeres y el restante $48,8 \%$ hombres. Calculamos, entonces, una gran cantidad de clientes potenciales para el proyecto.

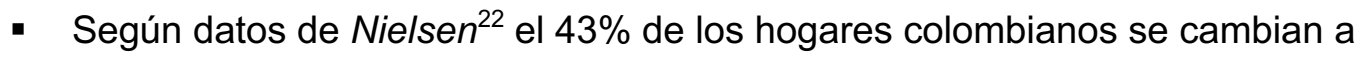
variedades saludables dentro de las mismas categorías que suelen consumir, lo que demuestra una tendencia en aumento hacia el consumo de alimentos sanos.

- El $59 \%{ }^{23}$ de los consumidores colombianos buscan productos bajos en azúcar y el $70 \%$ prefiere productos frescos; los frutos secos aparecen entonces como una alternativa saludable para reemplazar snacks y refrescos altos en calorías y escasos en nutrientes.

- Los frutos secos no figuran entre los principales cultivos en Colombia, el único cosechado en la región Caribe es la castaña de cajú (marañón), esto representa un gran potencial para el proyecto, ya que todos los frutos secos que actualmente se consumen son importados.

\footnotetext{
20 García, M. S (2014) Plan e informes de marketing internacional. (c.4, pp.28) España: IC Editorial

${ }^{21}$ Departamento Administrativo Nacional de estadísticas. (DANE) Recuperado de: https://id.presidencia.gov.co/Paginas/prensa/2019/190704-Poblacion-de-Colombia-es-de-48-2-milloneshabitantes-segun-DANE.aspx

${ }^{22}$ Nielsen Company. Recuperado de: https://www.nielsen.com/co/es/insights/article/2018/4-de-cada-10colombianos-estan-cambiando-a-la-version-saludable-de-su-producto-preferido/

${ }^{23}$ Nielsen Company. Recuperado de: https://www.nielsen.com/wpcontent/uploads/sites/3/2019/04/OnePageReportFoodRevolution2017.pdf
} 
- Los frutos secos son aptos para cualquier tipo de dieta, ya sea vegana u omnívora, lo que amplía la cartera de posibles clientes.

- Según el Departamento Nacional de Planeación (DNP) ${ }^{24}$, Colombia tendrá un crecimiento económico de 4,5\% para el 2022, lo que significa una oportunidad importante para una empresa que desea consolidarse en un país con un crecimiento económico estable y sostenido a largo plazo.

- Se estima que el consumo per cápita promedio de snacks saludables en Colombia es de 2 kilogramo por año ${ }^{25}$.

- El producto a comercializar no depende de estacionalidad, ya que es apto para consumir en cualquier época del año, siendo Navidad una de las que genera mayores ventas, ya que los frutos secos hacen parte de muchas preparaciones para celebrar esta temporada.

\subsection{Debilidades}

El análisis de las debilidades de una empresa, no se realiza desde un plano abstracto, sino siempre con referencia a los competidores más peligrosos, llamados prioritarios. ${ }^{26}$

Al ser una marca nueva que incursiona en mercado colombiano, es clave conocer los puntos débiles a través del análisis de los competidores en comparación con la Geven Frutos Secos.

Las debilidades de Geven Frutos Secos son:

\footnotetext{
${ }^{24}$ Departamento Nacional de Planeación (DNP). Recuperado de: https://www.dnp.gov.co/DNPN/Paginas/default.aspx ${ }^{25}$ Centro Virtual de Negocio (CVN). Recuperado de: https://www.cvn.com.co/wp-content/uploads/2018/08/4-Bebidas-alcoholicas-frutos-secos-1.pdf

${ }^{26}$ Lambin, J. J. (1995) Marketing Estratégico. (c.14, pp.583) Madrid: Mc Graw Hill
} 
- Poco capital para invertir, lo que es muy común cuando se cuenta con una idea nueva de negocio y no se posee el dinero necesario para emprender.

- Nueva marca desconocida, lo cual puede dificultar un poco la entrada al mercado destino colombiano.

- Siendo una empresa nueva en inicios de creación, será más complicado tener financiación por los entes financieros del país, siendo un factor débil para la comercializadora.

- Al ser una empresa nueva, durante los primeros tres años será necesario reinvertir la totalidad de las ganancias, para seguir creciendo hasta llegar al punto de equilibrio y más adelante incrementar los activos.

- Actualmente Geven Frutos Secos no cuenta con local físico propio de la marca.

- Necesidad de búsqueda de clientes interesados en comercializar los productos de Geven Frutos Secos en sus góndolas.

\subsection{Amenazas}

Para el análisis de las amenazas, deben ser cubiertos los siguientes campos: las tendencias del mercado, los comportamientos de los compradores, el entorno competitivo, las evoluciones del entorno y el contexto internacional ${ }^{27}$.

En un entorno tan cambiante tanto económicamente, como socialmente, es importante establecer los posibles factores externos que podrían impedir una llegada satisfactoria del producto a comercializar en el mercado colombiano.

Las amenazas encontradas para Geven Frutos Secos, son:

27 Lambin, J. J. (1995) Marketing Estratégico. (c.14, pp.576) Madrid: Mc Graw Hill 
- Mucha competencia existente en Colombia con alternativas de snacks saludables de alimentos, no necesariamente frutos secos. ${ }^{28}$

- Aún existe cierto desconocimiento o desconfianza por parte de algunos consumidores a los beneficios de los frutos secos para la salud, ya que en Colombia no son productos que se consumen diariamente y por el momento los precios son un tanto elevados. $^{29}$

- Aumento del precio internacional de los frutos secos, dada su alta demanda alrededor del mundo. ${ }^{30}$

- Poca estabilidad económica del país exportador: Argentina. ${ }^{31}$

- Se podrían presentar dificultades en la cosecha de frutos secos en Argentina, principalmente por cuestiones climáticas.

- Entrada de nuevos competidores al mercado de frutos secos en Colombia.

- Impacto ambiental del cultivo de frutos secos alrededor del mundo, esto debido a la nueva conciencia ecológica de los consumidores al momento de comprar un producto. $^{32}$

- El incremento de alergias de las personas a distintas variedades de los frutos secos. ${ }^{33}$

\footnotetext{
${ }^{28}$ En base a distintos sitios webs de comercializadoras y supermercados. Recuperado de: https://www.jumbo.com.ar/frutas-y-verduras, https://insualimentos.com/, https://www.exito.com/mercado/frutas-yverduras/frutas

${ }^{29}$ Nielsen Company. Recuperado de: https://www.nielsen.com/co/es/insights/article/2018/4-de-cada-10colombianos-estan-cambiando-a-la-version-saludable-de-su-producto-preferido/

${ }_{30}$ International Nut \& Dried Fruit Council (INC). Recuperado de: https://www.nutfruit.org/industry/technicalresources?category=statistical-yearbooks

31 Banco Mundial. Recuperado de: https://www.bancomundial.org/es/country/argentina/overview

${ }^{32}$ Ministerio de agricultura, Gobierno de chile (ODEPA). Recuperado de: https://www.odepa.gob.cl/wpcontent/uploads/2017/12/FrutosSecosSustantabilidad2017.pdf

${ }^{33}$ Asociación Española de personas con Alergias a Alimentos y Látex (AEPNAA). Recuperado de: https://www.aepnaa.org/ver/frutos-secos
} 
- Los productos sustitutos actuales no saludables en Colombia, podrían seguir teniendo mayor protagonismo en los consumidores, papas fritas, palitos de quesos, rosquitas de queso, conservas, entre otros. ${ }^{34}$

- Los costos elevados de distribución regional, debido a que en Colombia no se cuenta con una infraestructura vial adecuada para la comercialización entre las distintas regiones del país, generando posibles demoras en la entrega de los productos. ${ }^{35}$

- EL consumidor resulta ser muy sensible al precio, y este producto tiende ser un poco más costoso debido a su proceso de cultivo, importación y posterior distribución en Colombia. $^{36}$

\subsection{Conclusiones}

En este capítulo se estableció a manera de observación del mercado destino el análisis del FODA.

Se puede obtener un panorama general del mercado destino, un análisis que sirve para llevar a cabo las estrategias de marketing a emplear para la empresa, respetando los datos arrojados en las áreas del mercado actual, Geven Frutos Secos entraría a competir y con qué argumentos podría llegar.

Así mismo se puede percibir cómo encarar la segmentación del mercado, cuál será el público objetivo, cómo venderle el producto y qué cantidad debe ingerir cada persona, preferencia al momento de elegir un snack.

\footnotetext{
${ }^{34}$ Centro Virtual de Negocio (CVN). Recuperado de:
} https://www.cvn.com.co/wp-content/uploads/2018/08/4-Bebidas-alcoholicas-frutos-secos-1.pdf

${ }^{35}$ Instituto Nacional de Vías. Recuperado de: https://www.invias.gov.col

${ }^{36}$ En base a distintos sitios webs de comercializadoras y supermercados. Recuperado de: https://www.jumbo.com.ar/frutas-y-verduras, https://insualimentos.com/, https://www.exito.com/mercado/frutas-yverduras/frutas 


\section{SEGMENTACIÓN INTERNACIONAL DEL MERCADO}

En este capítulo se expondrá la segmentación internacional del mercado aplicable en la incursión de Geven Frutos Secos como comercializadora a Colombia.

La segmentación internacional se esfuerza en identificar los segmentos de compradores que, más allá de las fronteras nacionales, tienen actitudes, expectativas y comportamientos similares. En la medida en que los comportamientos y los estilos de vida se vuelven más homogéneos a través del mundo bajo el efecto del progreso económico, de los viajes y de la comunicación, segmentos de este tipo con expectativas homogéneas tienden a multiplicarse ${ }^{37}$.

Gracias a la globalización, el auge por un estilo de vida saludable ha conquistado todos los rincones del planeta. Cada día más personas se suman a cambiar sus hábitos, procurando realizar actividad física regular y consumir alimentos nutritivos, bajos en calorías.

Ante este panorama mundial, los frutos secos se posicionan como favoritos para reemplazar los snacks calóricos y también son incluidos en incontables preparaciones de platos saludables.

\subsection{Características del mercado internacional de frutos secos}

Estados Unidos concentra el $41 \%$ de la producción mundial de frutos secos, seguido de Turquía y China.

${ }^{37}$ Lambin, J. J. (1995) Marketing Estratégico. (c.6, pp.223) Madrid: Mc Graw Hill 


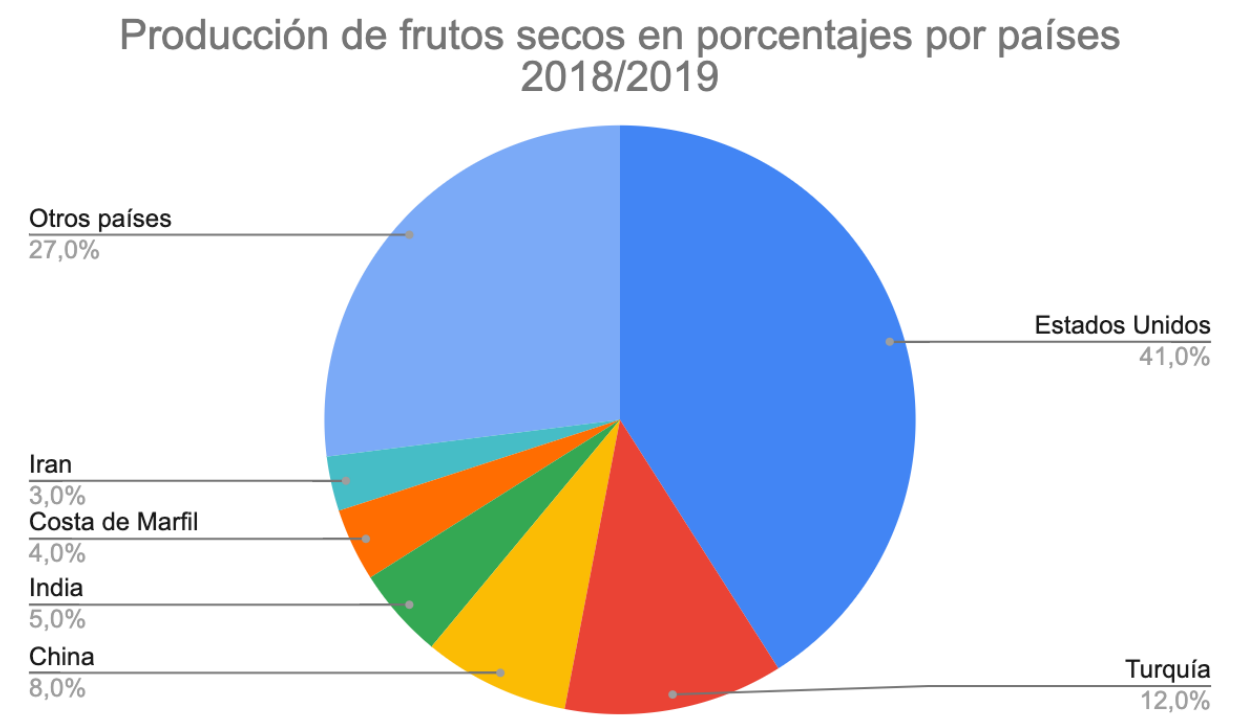

Esquema 2: Producción de los frutos secos en porcentajes por países 2018/2019

Fuente: Elaboración propia basada en datos de referencia ${ }^{38}$

En coherencia con lo anterior, Estados Unidos es el país con mayor consumo de frutos secos a nivel mundial, seguido de India y España.

${ }^{38}$ International Nut \& Dried Fruit Council (INC). Recuperado de: https://www.nutfruit.org/industry/technicalresources?category=statistical-yearbooks 


\section{Consumo estimado de frutos secos en toneladas métricas por} países, 2017

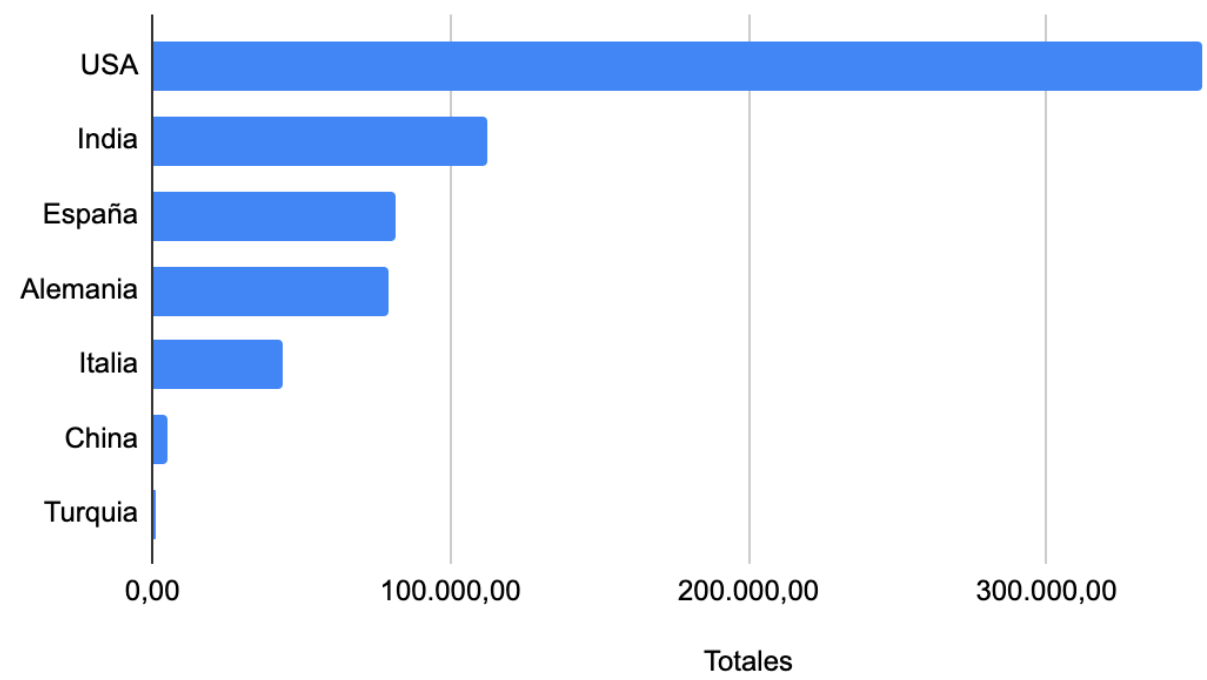

Esquema 3: Consumo estimado de frutos secos en toneladas métricas por países, 2017

Fuente: Elaboración propia basada en datos de referencia ${ }^{39}$

Según la $F A \mathrm{O}^{40}$ a nivel sudamericano, Chile, Argentina y Brasil destacan como productores y consumidores de frutos secos.

\subsection{Características principales del mercado de alimentos en Colombia}

Colombia $^{41}$ es el cuarto mercado más grande de América Latina, después de Brasil, México y Argentina. El 28\% de los alimentos que consumen los colombianos provienen del exterior, los principales países que lo abastecen son: Estados Unidos, Canadá y la Unión Europea, con los cuales tiene tratados de libre comercio.

\footnotetext{
${ }^{39}$ International Nut \& Dried Fruit Council (INC). Recuperado de: https://www.nutfruit.org/industry/technicalresources?category=statistical-yearbooks

$\frac{}{40}$ Organización de las Naciones Unidas para la Alimentación y la Agricultura. Recuperado de: http://www.fao.org/faostat/es/\#data/QC

41 Alimentos Argentinos. Recuperado de: http://www.alimentosargentinos.gob.ar/HomeAlimentos/Cadenas $\% 20$ de $\% 20$ Valor $\% 20$ de $\% 20$ Alimentos $\% 20 \mathrm{y} \% 20$ Bebidas/informes/Informe Mision a Colombia ALIMENTEC.pdf
} 
Según el Ministerio de Agroindustria Argentina ${ }^{42}$, el consumo en Colombia muestra un crecimiento anual del $7 \%$ cuando de alimentos y bebidas se trata, lo cual llevaría para los próximos períodos unos $\$ 25.000$ USD millones en 2021.

El sector de alimentos y bebidas alcanzó ventas en el mercado doméstico colombiano por $\$ 13.200$ USD millones en el 2017 con gran participación de las industrias de molinería, panadería y snacks, entre otros. ${ }^{43}$

Bogotá es el mayor centro de consumo en el país (57\%), seguido de Antioquia (15\%), Valle del Cauca (8\%), Bolívar (6\%) y Atlántico (5\%), principales provincias de Colombia.

\subsection{Características del mercado de los snacks en Colombia}

En Colombia, los frutos secos hacen parte del mercado de los "snacks", que se definen como los productos que son consumidos entre comidas o se incluyen en las meriendas que llevan los niños al colegio.

El consumo per cápita de snacks por habitante es de 2 kilogramos al año.

Colombia ${ }^{44}$ cuenta con un amplio mercado para los snacks, pero a pesar de que actualmente está dominado por productos calóricos como las papitas fritas y los chicharrones, cada vez toma más fuerza lo que se denomina frutos secos, ya que son muy energéticos, ricos en grasas buenas y proteínas. Lo anterior indica que los consumidores colombianos están interesados en productos que se consideran sanos y saludables, por eso las empresas existentes de snacks no saludables han respondido a esta nueva demanda mediante la ampliación de su oferta con frutos secos.

\footnotetext{
${ }^{42}$ Alimentos argentinos. Recuperado de: http://www.alimentosargentinos.gob.ar/HomeAlimentos/Nutricion/fichaspdf/Ficha 54 Frutos Secos.pdf

${ }^{43}$ Centro Virtual de Negocio (CVN). Recuperado de:

https://www.cvn.com.co/wp-content/uploads/2018/08/4-Bebidas-alcoholicas-frutos-secos-1.pdf 44 PROCOLOMBIA. Exportaciones Turismo Inversión Marca País. Recuperado de: https://tlceeuu.procolombia.co/oportunidades-por-sector/agroindustria/pasabocas-o-snacks
} 


\subsection{Oportunidad comercial entre Argentina y Colombia}

Gracias al Acuerdo de Complementación Económica No. 59 entre MERCOSUR y la CAN $(A L A D I)^{45}$, existen preferencias arancelarias para las exportaciones e importaciones entre Argentina y Colombia.

Según datos del Instituto Nacional de Estadísticas (INDEC) las exportaciones desde Argentina a Colombia, en el periodo comprendido del 2015 al 2018 se han incrementado un $64,19 \%$.

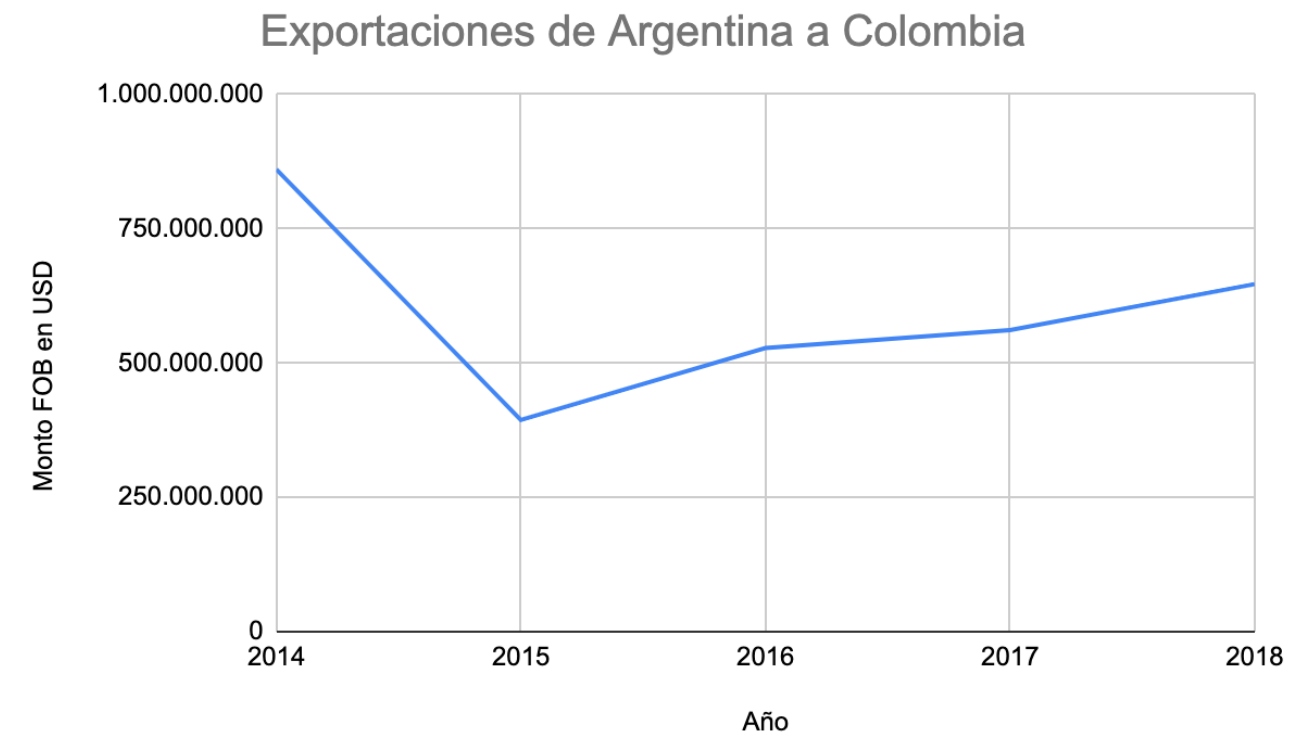

Esquema 4: Exportaciones de Argentina a Colombia

Fuente: Elaboración propia basada en datos de referencia ${ }^{46}$

A continuación, las exportaciones argentinas de frutas secas o procesadas a Colombia en el período comprendido entre 2014 y 2018 :

\footnotetext{
${ }^{45}$ ALADI. Acuerdo de Complementación Económica MERCOSUR. Recuperado de: http://www2.aladi.org/biblioteca/Publicaciones/ALADI/Acuerdos/ACE/ES/ACE72/ACE 072.pdf

46 Instituto Nacional de Estadísticas. (INDEC) Recuperado de: https://opex.indec.gov.ar/index.php?pagina=mapa dinamico
} 


\section{Exportaciones argentina de frutas secas o procesadas a}

Colombia

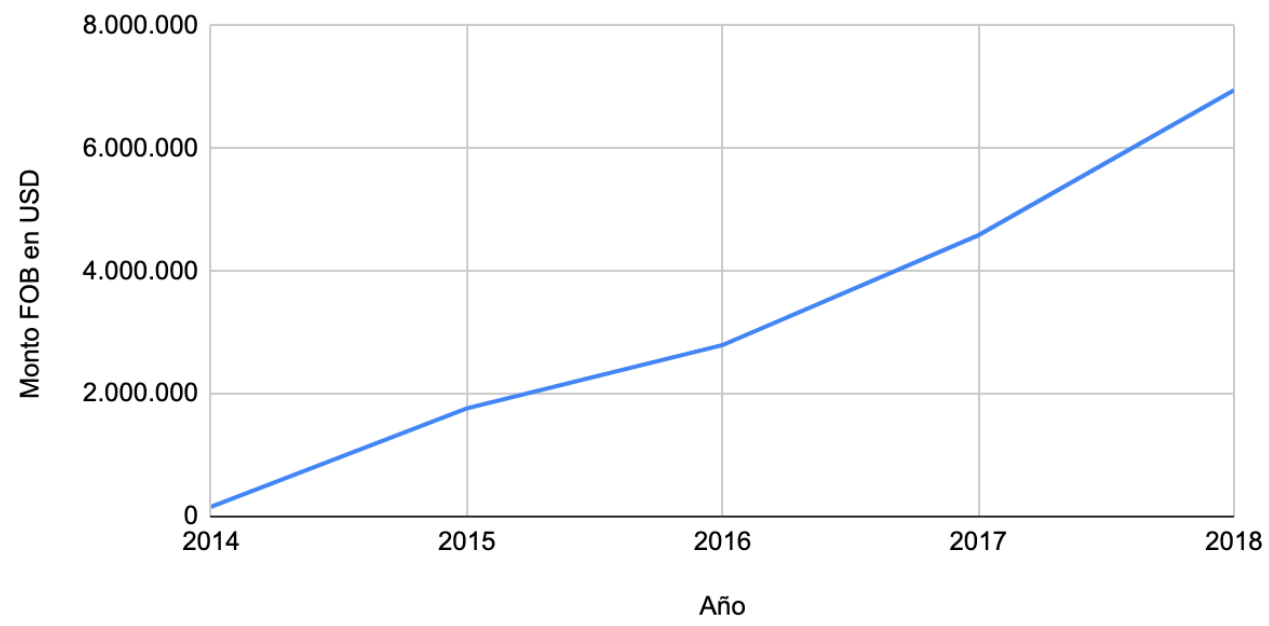

Esquema 5: Exportaciones Argentina de frutas secas o procesadas a Colombia

Fuente: Elaboración propia basada en datos de referencia ${ }^{47}$

Se puede evidenciar que el aumento en las exportaciones de estos productos, desde Argentina a Colombia, es de $4.276,89 \%$

4.5. Conceptualización del mercado colombiano de referencia

- El ámbito de actividad de Geven Frutos Secos es el sector de alimentos, más específicamente de snacks saludables en Colombia.

- Las necesidades a satisfacer de Geven Frutos Secos es ofrecer soluciones de alimentación rápidas, prácticas y saludables.

- Los grupos potenciales interesados por el producto de Geven Frutos Secos, son todas esas personas que -en el día a día- mantienen una dieta balanceada, se ejercitan, trabajan muchas horas, están muy informados sobre los nutrientes que aporta cada alimento que consumen, buscando que sea lo más natural posible.

47 Instituto Nacional de Estadísticas. (INDEC) Recuperado de: https://opex.indec.gov.ar/index.php?pagina=mapa dinamico 


\subsection{Segmentación sociodemográfica}

La población total en Colombia ${ }^{48}$ actualmente es de 48,2 millones de habitantes, con un porcentaje de $51,2 \%$ mujeres y el restante $48,8 \%$ hombres.

El 22,6\% de los colombianos se ubican entre los 0 - 14 años; el $68,2 \%$ entre los 15 y 65 años y el $9,1 \%$ tiene más de 65 años.

Por cada 100 jóvenes menores de 15 años, hay 40 personas mayores de 65 años en el país.

\subsection{Mercado objetivo de Geven Frutos Secos}

El mercado objetivo de Geven Frutos Secos corresponde a hombres y mujeres colombianos desde los 18 años de edad, de nivel socioeconómico medio-alto y alto.

Geven Frutos Secos se dirige personas activas, que practican actividad física regular, acostumbran preparar sus alimentos en casa o prefieren visitar restaurantes con opciones saludables, les interesa mantenerse al día con noticias relacionadas a la alimentación, la salud y el deporte.

\subsection{Conclusiones}

En este capítulo se abordaron los campos de segmentación internacional de Geven Frutos Secos, y el mercado destino Colombia; los resultados arrojaron que se viene dando una tendencia en el mundo de consumo saludable, una oportunidad para las marcas que desean invertir en este segmento.

${ }^{48}$ Departamento Administrativo Nacional de estadísticas. (DANE) Recuperado de: https://id.presidencia.gov.co/Paginas/prensa/2019/190704-Poblacion-de-Colombia-es-de-48-2-milloneshabitantes-segun-DANE.aspx 
Las cifras de comercio exterior entre Argentina y Colombia muestran un considerable aumento en las exportaciones de frutas secas o procesadas, lo que evidencia también la tendencia del mercado hacia este tipo de productos.

La información recopilada sirve para organizar los objetivos internacionales del proyecto y las decisiones en cuanto a las distintas variables del Marketing Mix. 


\section{OBJETIVOS PARA LA COMERCIALIZACIÓN INTERNACIONAL}

El fin de este capítulo es el establecimiento de los objetivos de Marketing Internacional para la empresa Geven Frutos Secos, cuidando que los mismos tengan las siguientes características $^{49}$ :

- Que estén supeditados a los objetivos y estrategias del Plan Estratégico General de la empresa.

- Que estén basados en las fases anteriores de análisis y diagnóstico de la situación.

- Sean adecuados, motivadores, realistas, alcanzables y coherentes entre sí.

El análisis de las fases anteriores de este Plan de Marketing Internacional, permiten llegar a los siguientes 4 objetivos para Geven Frutos Secos:

- Posicionar la marca Geven Frutos Secos en Colombia obteniendo una notoriedad del $40 \%$ en los consumidores a partir de los 18 años de edad.

- Alcanzar en un año el 5\% del mercado de los snacks saludables en Colombia.

- Conseguir una tasa de crecimiento del 5\% anual sobre la inversión en el término de un año.

- Concretar un promedio de ventas de dos toneladas anuales en los próximos 3 años a partir de 2021.

Se lograron estipular los objetivos que planea cumplir la empresa, con el fin de establecerse y consolidarse en el mercado colombiano de snacks saludables.

${ }^{49}$ Carpintero, L. (2014) Plan e informes de marketing internacional. España: (c.1, pp.20) Ediciones Paraninfo S.A. 
Los objetivos para la comercialización constituyen el punto de partida para la creación de las estrategias de marketing internacional. 


\section{ESTRATEGIAS DE MARKETING INTERNACIONAL}

En el desarrollo de este capítulo se expondrán las estrategias de marketing internacional establecidas para poder lograr los objetivos expuestos en el capítulo anterior.

La estrategia de marketing internacional elegida para este proyecto es la estrategia funcional, porque combina los diferentes medios e instrumentos de marketing que dispone una organización (Marketing Mix), pilar fundamental para una empresa que está iniciando un proceso de internacionalización. ${ }^{50}$

Las partes del Marketing Mix abarcan:

- Productos: amplitud de gama, política de marca e imagen de marca.

- Precios: estrategia de precios, cobertura del mercado.

- Comunicación: mensajes, medios, soportes.

- Distribución y ventas: sistema de ventas, localización de puntos de venta, cobertura del mercado.

\subsection{Política de producto}

Los productos y servicios son el punto de partida en la planeación del Marketing Mix. La política de producto engloba el total de atributos, tanto físicos como psicológicos, que el consumidor percibe de un bien tangible o servicio en orden de satisfacer sus necesidades y deseos. $^{51}$

50 Carpintero, L. (2014) Plan e informes de marketing internacional. España: (c.1, pp.35) Ediciones Paraninfo S.A.

${ }^{51}$ Alvarez, L. C (2016). Plan de marketing empresarial. (cc.2, pp.33) Madrid: Ediciones Paraninfo 
Para la comercialización del producto, Geven Frutos Secos inicialmente exportará desde Argentina a Colombia 600 kilos por especie distribuidos en 12 sacos de 50 kilos cada uno, con las tres variedades escogidas: nueces de nogal, nueces de pecán y pistachos. Las mismas serán fraccionadas y empacadas en el país destino, en presentaciones de 100 gramos cada una, para luego ser comercializadas entre mayoristas del sector como supermercados.

\subsubsection{Empacado y fraccionamiento del producto en Colombia}

De acuerdo con lo estipulado en la Resolución 683 de 2012 emitida por el Ministerio de Salud y Protección Social en Colombia ${ }^{52}$ sobre los requisitos sanitarios que deben cumplir los materiales, objetos, envases y equipamientos destinados a entrar en contacto con alimentos y bebidas para el consumo humano establece lo siguiente:

- Los materiales y objetos no activos no deben alterar la composición de los productos.

- Se prohíben los materiales con: costales de fibras naturales o sintéticas, que no sean de primer uso; envases de madera que no sean de primer uso; tapones y otros objetos de corcho, que no sean de primer uso; materiales recuperado pos consumo de descarte industrial; recipientes, envases o embalajes que contengan leyendas de otros productos.

- Se permite el uso de materiales reciclados.

- Las instalaciones destinadas al fraccionamiento y empacado de los productos deben estar ubicadas en lugares aislados de cualquier foco de insalubridad o contaminación; sus accesos y alrededores deben mantenerse limpios y su funcionamiento no debe poner en riesgo la salud y el bienestar de la comunidad.

- Las materias primas utilizadas en los empaques deben ser de buena calidad técnica de acuerdo a los criterios de pureza.

52 Resolución 683 de 2012. Ministerio de Salud Colombia. Recuperado de: https://www.minsalud.gov.co/sites/rid/Lists/BibliotecaDigital/RIDE/DE/DIJ/resolucion-0683-de-2012.pdf 
- Se debe contar con áreas de almacenamiento exclusivos para almacenar insumos y objetos que luego tengan contacto con alimentos para el consumo humano.

En sintonía con lo anterior, la empresa elegida para llevar a cabo el proceso de fraccionamiento, empacado y comercialización es la empresa FRUTCOM SAS con domicilio en Colombia, la cual figura en el Directorio de Importadores del año 2019 de la Dirección de Impuestos y Aduanas Nacionales (DIAN).

6.1.2. Atributos y características del producto

Los frutos secos se denominan así por poseer escasa agua en su composición, tener cáscara dura, ya sea por deshidratación o naturalmente y son crocantes al paladar. A diferencia de otro fruto natural, los frutos secos tienen un mayor tiempo de cosecha y duración, por lo que no requieren conservantes artificiales, basta con mantenerlos en un lugar limpio y fresco..$^{53}$

6.1.2.1. Nuez de Nogal

${ }^{53}$ International Nut \& Dried Fruit Council (INC). Recuperado de: https://www.nutfruit.org/industry/technicalresources?category=statistical-yearbooks 


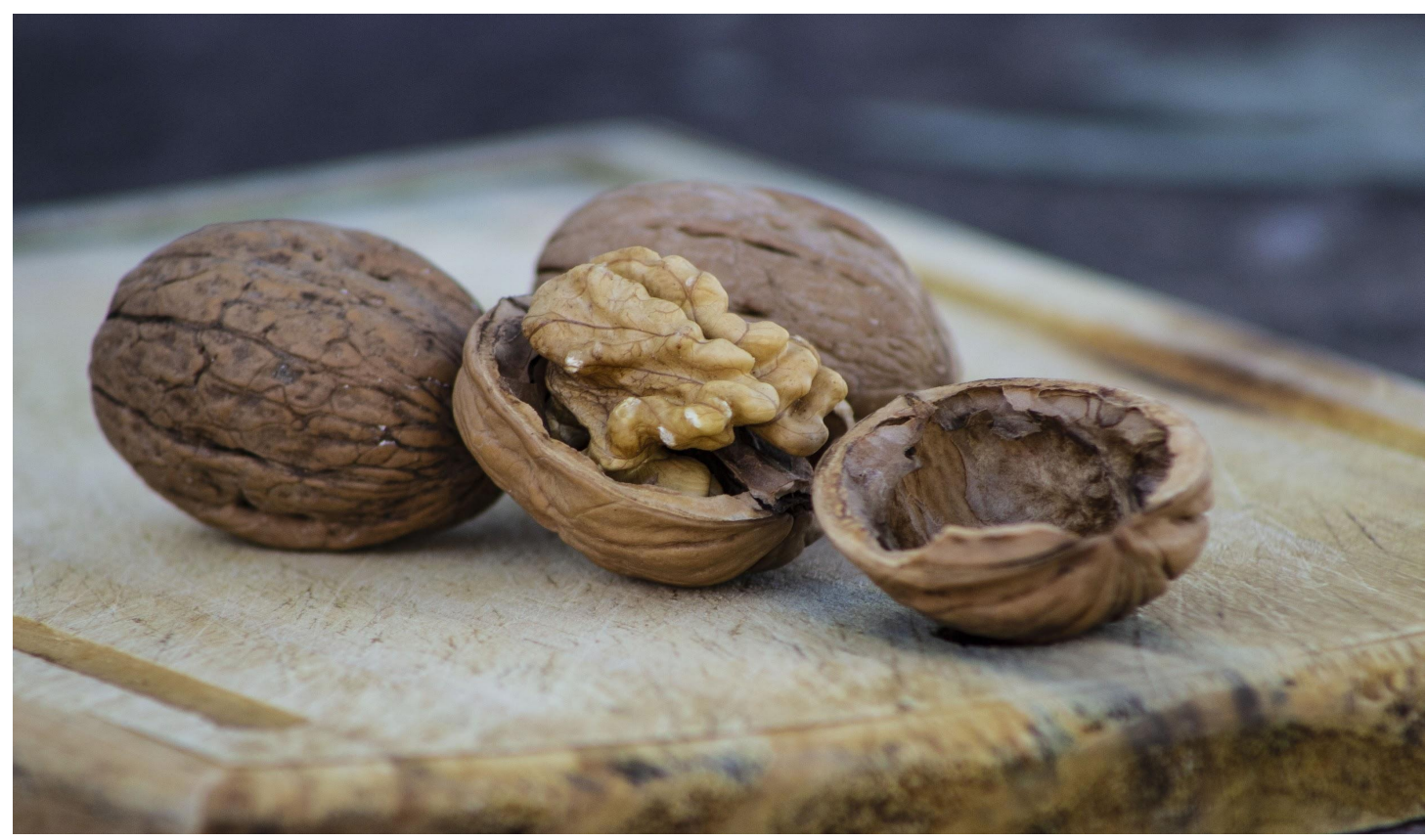

llustración 1: Fotografía de nueces de nogal

Fuente: elaboración propia.

Es un fruto que nace del árbol Juglans regia. Posee un tamaño semicircular, muchas grietas de forma estrías, con una cáscara dura, en su interior contiene el fruto comestible, de textura crocante y sabor suave.

Las nueces son ricas en grasas poliinsaturadas ${ }^{54}$ altas en fibra, tiamina, vitaminas B6, minerales como el magnesio, zinc. Comer 30 gramos al día contribuye a una buena elasticidad de los vasos sanguíneos.

Las nueces también ayudan a prevenir enfermedades cardiovasculares, mantener control del colesterol malo y las arterias limpias.

Información nutricional nuez nogal por 100 gramos

Calorías

$691 \mathrm{kcal}$

${ }^{54}$ Consejo Internacional de Frutos Secos (INC). Recuperado de: https://www.nutfruit.org/consumers/about-nuts/walnut 


\begin{tabular}{|l|l|}
\hline Grasas saturadas & $6,6 \mathrm{~g}$ \\
\hline Grasas trans & $0 \mathrm{~g}$ \\
\hline Colesterol & $0 \mathrm{~g}$ \\
\hline Sodio & $0 \mathrm{~g}$ \\
\hline Carbohidratos & $13,86 \mathrm{~g}$ \\
\hline Fibra dietética & $9,6 \mathrm{~g}$ \\
\hline Azúcar & $3,97 \mathrm{~g}$ \\
\hline Proteína & $9,17 \mathrm{~g}$ \\
\hline
\end{tabular}

Tabla 2: Información nutricional nuez nogal por 100 gramos

Fuente: Consejo Internacional de Frutos Secos (INC) $)^{55}$

${ }^{55}$ Consejo Internacional de Frutos Secos (INC). Recuperado de: https://www.nutfruit.org/consumers 


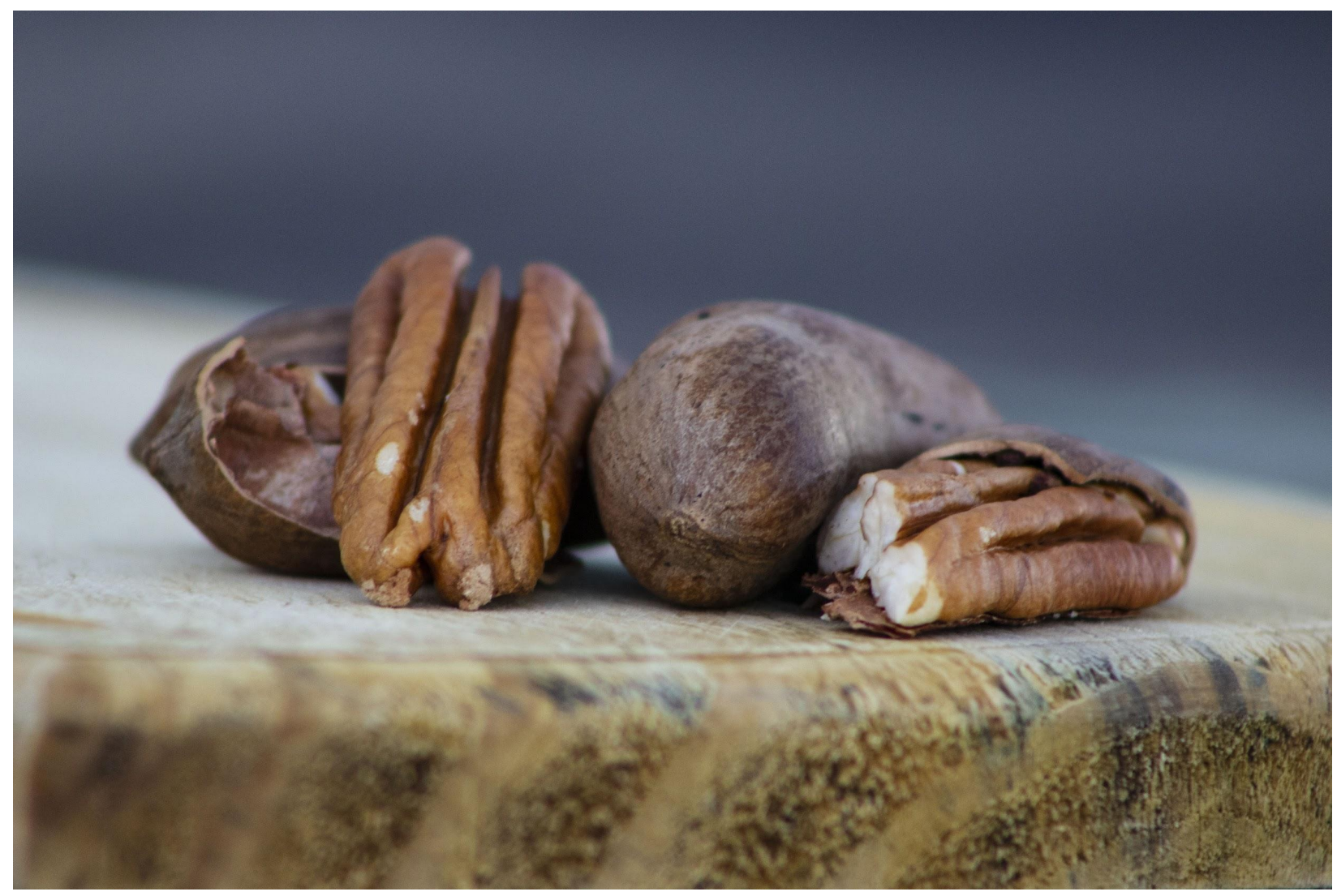

llustración 2: Fotografía de nueces de pecán.

Fuente: elaboración propia.

Proviene del árbol Carya illinoinensis de 30 metros de altura y 2 metros de ancho de la familia Juglans o pecana común. De color marrón claro, tiene una figura ovalada, textura lisa, en su parte exterior tiene una cáscara dura y en su interior contiene el fruto de ranuras a lo largo de su tamaño ovalado, color marrón un poco más oscuro que su cáscara, suave y crocante al paladar.

Las nueces pecanas son alimentos muy saludables, utilizados para gran variedad de recetas culinarias y exquisitos platos. Contienen vitamina B1, ayudando a las funciones normales del corazón, grasas monoinsaturadas, reduce riesgos de enfermedad cardiometabólica, no son solamente saludables para el corazón, también son una de las fuentes vegetales más ricas de antioxidantes y polifenólicos que ayudan a reponer las células dañadas. ${ }^{56}$

56 Consejo Internacional de Frutos Secos (INC). Recuperado de: https://www.nutfruit.org/consumers/about-nuts/pecan 


\begin{tabular}{|l|l|}
\hline \multicolumn{2}{|l|}{ Información nutricional nuez pecán por 100 gramos } \\
\hline Calorías & $691 \mathrm{kcal}$ \\
\hline Grasas totales & $71,97 \mathrm{~g}$ \\
\hline Grasas trans & $0 \mathrm{~g}$ \\
\hline Colesterol & $0 \mathrm{~g}$ \\
\hline Sodio & $0 \mathrm{~g}$ \\
\hline Carbohidratos & $13,86 \mathrm{~g}$ \\
\hline Fibra dietética & $9,6 \mathrm{~g}$ \\
\hline Azúcar & $0 \mathrm{~g}$ \\
\hline Proteína & $9,17 \mathrm{~g}$ \\
\hline
\end{tabular}

Tabla 3: Información nutricional nuez pecán por 100 gramos.

Fuente: Consejo Internacional de Frutos Secos (INC) $)^{57}$

${ }^{57}$ Consejo Internacional de Frutos Secos (INC). Recuperado de: https://www.nutfruit.org/consumers 


\subsubsection{Pistacho}

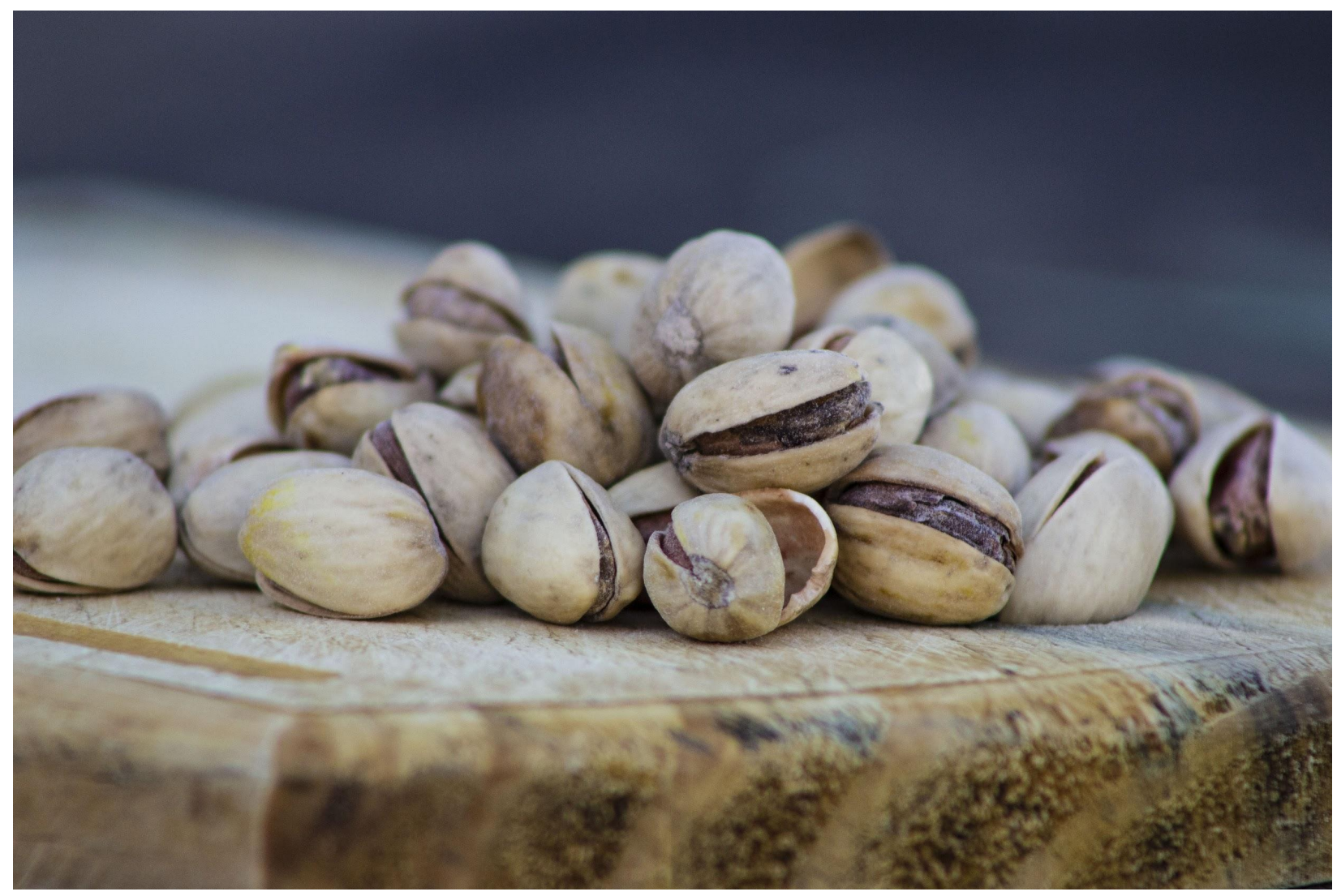

Ilustración 3: Fotografía de pistachos.

Fuente: elaboración propia.

Es un fruto seco de tamaño pequeño y alargado, proviene del árbol Pistacia vera. En su exterior tiene una cáscara dura y lisa de color marrón claro, en su interior tiene la semilla que es la parte comestible de tonos verdoso y pálido con texturas uniformes, de sabor dulce y delicado al paladar.

El pistacho aporta cantidades significativas de grasas monoinsaturadas, vitaminas B6, tiamina y minerales como fósforo, magnesio, potasio y cobre, también son fuentes de proteínas y energéticos. 
Contiene un efecto en reductor de glucosa e insulina de azúcar en la sangre. Comer pistachos todos los días reduce las probabilidades de sufrir problemas de obesidad asociada a la diabetes en adultos tipo $2 .^{58}$

\section{Información nutricional pistacho por 100 gramos}

\begin{tabular}{|l|l|}
\hline Calorías & $572 \mathrm{kcal}$ \\
\hline Grasas totales & $45,82 \mathrm{~g}$ \\
\hline Grasas trans & $0 \mathrm{~g}$ \\
\hline Colesterol & $0 \mathrm{~g}$ \\
\hline Sodio & $0,6 \mathrm{~g}$ \\
\hline Carbohidratos & $28,28 \mathrm{~g}$ \\
\hline Fibra dietética & $10,3 \mathrm{~g}$ \\
\hline Azúcar & $7,74 \mathrm{~g}$ \\
\hline Proteína & $21,05 \mathrm{~g}$ \\
\hline
\end{tabular}

Tabla 4: Información nutricional pistacho por 100 gramos.

Fuente: Consejo Internacional de Frutos Secos (INC) $)^{59}$

\subsubsection{Clasificación del producto}

Según su naturaleza, los frutos secos se clasifican en productos tangibles no duraderos, muy a pesar de tener una mayor duración posterior a su recolecta y distribución al mercado, comparado con las frutas frescas.

\footnotetext{
${ }^{58}$ Consejo Internacional de Frutos Secos (INC) Recuperado de: https://www.nutfruit.org/consumers/aboutnuts/pistachio

${ }_{59}$ Consejo Internacional de Frutos Secos (INC). Recuperado de: https://www.nutfruit.org/consumers
} 
Según su uso final, los frutos secos son de consumo habitual, ya que es algo que el consumidor puede adquirir regularmente en su compra mensual, o eventualmente para consumir como snack. ${ }^{60}$

Según su motivo de compra, los frutos secos son racionales, es decir, su consumidor promedio es una persona que se programa anticipadamente para adquirir la ración que necesita ya sea para meriendas o para alguna receta en específico. ${ }^{61}$

Según su comprador, los frutos secos comercializados por Geven Frutos Secos inicialmente serán para mayoristas, se dispondrá de cajas de 50 unidades de 100 gramos por unidad.

\subsubsection{Gama y línea de productos}

Para iniciar la incursión en el mercado colombiano, Geven Frutos Secos proveerá a su público de 3 variedades de frutos secos: nueces pecanas, nueces de nogal y pistachos.

La profundidad de los productos ofrecidos es de 2 líneas:

- Especie nuez: nueces de nogal y nueces de pecán

- Pistachos

\subsubsection{Posicionamiento del producto}

- Los atributos a resaltar de los frutos secos que comercializa Geven Frutos Secos son, básicamente, sus beneficios para la salud y la practicidad en su uso.

- Según la investigación de la competencia, la mayoría de frutos secos que se comercializan en Colombia, provienen de USA dando esa distinción de importado por

\footnotetext{
${ }^{60}$ Consejo Internacional de Frutos Secos (INC). Recuperado de: https://www.nutfruit.org/consumers/about-nuts/pecan

${ }^{61}$ Centro Virtual de Negocio (CVN). Recuperado de: https://www.cvn.com.co/wp-content/uploads/2018/08/4-Bebidas-alcoholicas-frutos-secos-1.pdf
} 
empresas extranjeras, se hará hincapié en resaltar que son snacks, más allá de sus beneficios para la salud. ${ }^{62}$

- La ventaja competitiva de Geven Frutos Secos es que las 3 especies a comercializar inicialmente en Colombia, no se cultivan en el país ${ }^{63}$, y, por ende, son exportadas de Argentina con los más altos estándares de calidad, transmitiendo una imagen joven, fresca y vanguardista.

- La estrategia elegida para posicionar Geven Frutos Secos es por el estilo de vida, ya que apuntamos a un target muy específico de personas que se alimentan bien, se preocupan por su salud y prefieren las variedades "light" de los productos.

Declaración de posicionamiento:

Para personas activas que prefieren alimentarse saludablemente, Geven Frutos Secos es la opción de snacks prácticos, naturales y accesibles.

\subsubsection{Diseño de la marca:}

\section{LOGOTIPO}

Para la creación de la marca se utilizaron los colores verdes de tonalidades pasteles y grises, con tipografías de trazos carácter fuerte y decisivo, incluyendo hojas verdes en posición diagonal y mezclados con las letras $\mathrm{G}$ y E, evocando la esencia natural y saludable de los productos que comercializa Geven Frutos Secos.

\footnotetext{
62 En base a distintos sitios webs de comercializadoras y supermercados. Recuperado de: https://www.jumbo.com.ar/frutas-y-verduras, https://insualimentos.com/, https://www.exito.com/mercado/frutas-yverduras/frutas

${ }^{63}$ Ministerio de Agricultura y Desarrollo Rural. Recuperado de: https://www.agronet.gov.co/Paginas/inicio.aspx
} 


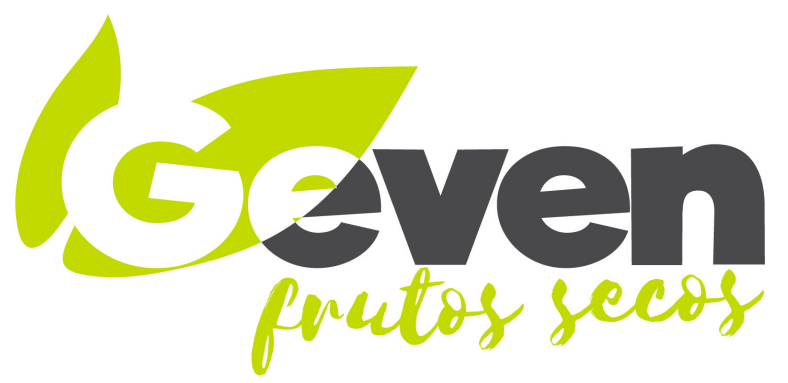

Ilustración 4: Diseño de logotipo

Fuente: elaboración propia.

Estrategia de la marca

Packaging: el diseño está inspirado en mostrar el producto en su total naturalidad, frescura, de buena calidad sin perder nunca de vista lo que quiere transmitir la marca, transparencias que permita ver el fruto, que el consumidor sepa realmente qué es lo va a comprar. 

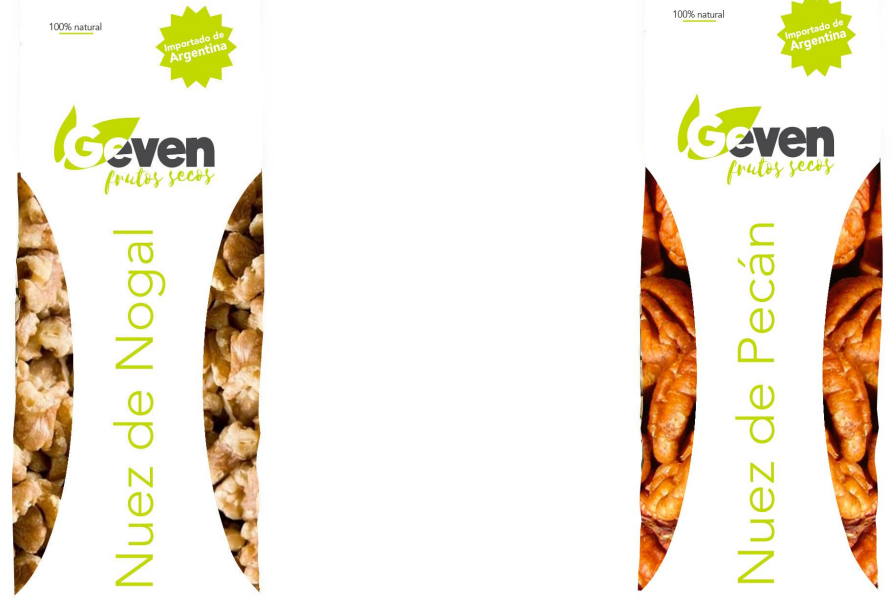

100 gramos

100 gramos
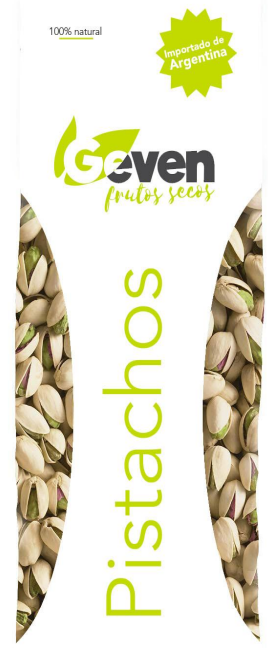

100 gramos

llustración 5: Muestra de diseño de empaques.

Fuente: elaboración propia.

\subsubsection{Etiquetado del producto}


En Colombia, de acuerdo con lo establecido por el Instituto Nacional de Vigilancia de Medicamentos y Alimentos (INVIMA $)^{64}$, en lo referente a etiquetado o rotulado de alimentos para el consumo, las etiquetas deben contener la siguiente información:

- Nombre del alimento

- Contenido neto

- Nombre y dirección del importador

- Nombre y dirección del fraccionador, re envasador o empacador

- Número o código del lote de producción

- Fecha de vencimiento y/o duración mínima

- Sistema de conservación

- Tabla de composición nutricional (a partir de 2022).

6.2. Política de precio:

El precio y sus modificaciones sustanciales son elementos de acción a corto plazo en cualquier estrategia de marketing, no solo se incluye el costo monetario que un cliente está dispuesto a pagar por un producto o servicio, sino también el esfuerzo que implica llegar a tener el bien.

Se puede considerar que el precio tiene una serie de interpretaciones a través de los consumidores que le hacen ser fuente de diferenciación y un estímulo directo para la demanda, ya que, es el único elemento del Marketing Mix que proporciona ingresos a la empresa ${ }^{65}$.

6.2.1. Precio promedio de los principales competidores en Colombia

\footnotetext{
64 Instituto Nacional de Vigilancia de Medicamentos y Alimentos. INVIMA. Recuperado de: https://www.invima.gov.co/documents/20143/1402493/26.+Instructivo+para+la+Vigilancia+del+Rotulado+de+Alim entos $\% 2 \mathrm{C}+$ Bebidas+y+sus+Materias+Primas.pdf

${ }^{65}$ Alvarez, L. C (2016). Plan de marketing empresarial. (cc.3, pp.57) Madrid: Ediciones Paraninfo
} 
A continuación, se expone una tabla comparativa con los precios de los principales competidores para cada uno de los frutos secos a comercializar en Colombia:

\begin{tabular}{|l|l|l|}
\hline \multicolumn{3}{|l|}{ Precio principales competidores de nueces de nogal x 100 gramos } \\
\hline Marca & COP & USD \\
\hline Insualimentos & 13.200 & 3,88 \\
\hline Pomona & 10.250 & 3,01 \\
\hline Vitamento & 11.000 & 3,23 \\
\hline
\end{tabular}

Tabla 5: Precio de los principales competidores de nuez de nogal.

Fuente: elaboración propia basada en datos de referencia ${ }^{66}$.

El precio promedio por 100 gramos de nueces de nogal en Colombia es de USD 3,37

\begin{tabular}{|l|l|l|}
\hline \multicolumn{2}{|l|}{ Precio principales competidores de nueces de pecán x 100 gramos } \\
\hline Marca & COP & USD \\
\hline Vitamento & 13.000 & 3,82 \\
\hline Insualimentos & 22.500 & 6,61 \\
\hline Jumbo & 17.300 & 5,08 \\
\hline
\end{tabular}

Tabla 6: Precio principales competidores de nuez de pecán.

${ }^{66}$ En base a distintos sitios webs de comercializadoras y supermercados. Recuperado de: https://www.jumbo.com.ar/frutas-y-verduras, https://insualimentos.com/, https://www.exito.com/mercado/frutas-yverduras/frutas 
Fuente: elaboración propia basada en datos de referencia ${ }^{67}$

El precio promedio por 100 gramos de nueces de pecán en Colombia es de USD 5,17.

\begin{tabular}{|l|l|l|}
\hline \multicolumn{2}{|l|}{ Precio principales competidores de pistachos $\times 100$ gramos } \\
\hline Marca & COP & USD \\
\hline Nature's Heart & 11.200 & 3,29 \\
\hline Insualimentos & 16.050 & 4,72 \\
\hline Flavor's House & 14.200 & 4,17 \\
\hline
\end{tabular}

Tabla 7: Precio principales competidores de pistacho.

Fuente: elaboración propia basada en datos de referencia ${ }^{68}$

El precio promedio por 100 gramos de pistachos en Colombia es de USD 4,06.

Los precios anteriores sirven como referencia del panorama del mercado para las nueces de nogal, nueces de pecán y pistachos en Colombia, base importante para definir el precio de los productos de Geven Frutos Secos.

\subsubsection{Objetivo de precio}

El objetivo de precio para Geven Frutos Secos es la maximización de las utilidades, teniendo en cuenta que, al ser una empresa nueva, necesita hacer una penetración del mercado colombiano y a la vez recuperar la inversión, en sintonía con los objetivos del plan

${ }^{67}$ En base a distintos sitios webs de comercializadoras y supermercados. Recuperado de: https://www.jumbo.com.ar/frutas-y-verduras, https://insualimentos.com/, https://www.exito.com/mercado/frutas-yverduras/frutas

${ }^{68}$ En base a distintos sitios webs de comercializadoras y supermercados. Recuperado de: https://www.jumbo.com.ar/frutas-y-verduras, https://insualimentos.com/, https://www.exito.com/mercado/frutas-yverduras/frutas 
estratégico de marketing. Lo anterior, sin perder de vista el resto de elementos que componen el Marketing Mix y la intención de construir una marca sólida y coherente.

La estrategia de precios elegida para comercializar los frutos secos es la fijación de precios basada en el valor percibido, ya que se utilizarán otros elementos del marketing mix para comunicar y convencer al cliente de elegir a Geven Frutos Secos porque ofrece un valor adicional a la competencia.

Para llevar a cabo lo anterior, se partirá de la construcción de la marca, el packaging, los canales de distribución, la publicidad online y buscando siempre una percepción de calidad premium, logrando crear un vínculo emocional con los clientes.

A continuación, una tabla con los costos operativos de exportación e importación de 600 kilos de mercadería (200 kilos por especie) de nueces de nogal, nueces de pecán y pistachos desde Argentina a Colombia.

\begin{tabular}{|l|l|}
\hline \multicolumn{2}{|l|}{ INFORMACIÓN BÁSICA DEL PRODUCTO } \\
\hline NUECES DE NOGAL & Nueces de nogal sin cáscara \\
\hline $\begin{array}{l}\text { Nombre técnico o comercial del } \\
\text { producto }\end{array}$ & 0802.32 .00 .00 \\
\hline $\begin{array}{l}\text { Posición arancelaria del país } \\
\text { exportador }\end{array}$ & 0802.32 .00 .01 \\
\hline $\begin{array}{l}\text { Posición arancelaria del país } \\
\text { importador }\end{array}$ & 200 kilos \\
\hline Unidad comercial de venta & 4.019 \\
\hline Valor FOB de la unidad comercial & Dólar estadounidense \\
\hline Moneda & Nueces de pecán sin cáscara \\
\hline NUECES DE PECÁN & \\
\hline Nombre técnico o comercial del \\
producto
\end{tabular}




\begin{tabular}{|l|l|}
\hline $\begin{array}{l}\text { Posición arancelaria del país } \\
\text { exportador }\end{array}$ & 0802.90 .00 \\
\hline $\begin{array}{l}\text { Posición arancelaria del país } \\
\text { importador }\end{array}$ & 0802.90 .01 \\
\hline Unidad comercial de venta & 200 kilos \\
\hline Valor FOB de la unidad comercial & 3.384 \\
\hline Moneda & Dólar estadounidense \\
\hline PISTACHOS & Pistachos con cáscara \\
\hline $\begin{array}{l}\text { Nombre técnico o comercial del } \\
\text { producto }\end{array}$ & 0802.51 .00 \\
\hline $\begin{array}{l}\text { Posición arancelaria del país } \\
\text { exportador }\end{array}$ & 0802.51 .01 \\
\hline $\begin{array}{l}\text { Posición arancelaria del país } \\
\text { importador }\end{array}$ & 200 kilos \\
\hline Unidad comercial de venta & 3.173 \\
\hline Valor FOB de la unidad comercial & Dólar estadounidense \\
\hline Moneda &
\end{tabular}

Tabla 8: Información básica de los productos a exportar.

Fuente: elaboración propia a partir de información tomada de la tesis "Proyecto de exportación de frutos secos" de la maestranda Gheraldine Mancilla.

\begin{tabular}{|l|l|}
\hline INFORMACIÓN BÁSICA DEL EMBARQUE \\
\hline País origen & Argentina \\
\hline Puerto de embarque & Buenos Aires \\
\hline País destino & Colombia \\
\hline Puerto de desembarque & Cartagena \\
\hline Total cantidad de kilos a exportar & 600 \\
\hline
\end{tabular}




\begin{tabular}{|l|l|}
\hline Tipo de empaque/embalaje & Bolsas de plástico empacadas al vacío \\
\hline Unidad de carga & Bolsas de 25 kilos \\
\hline Dimensiones de la unidad de carga & $60 \times 50 \times 15 \mathrm{~cm}$ \\
\hline Acondicionamiento de la carga & 1 pallet americano \\
\hline
\end{tabular}

Tabla 9: Información básica del embarque.

Fuente: elaboración propia a partir de información tomada de la tesis "Proyecto de exportación de frutos secos" de la maestranda Gheraldine Mancilla.

\begin{tabular}{|l|l|l|}
\hline COSTOS DE EXPORTACIÓN & $\%$ & USD \\
\hline Costo de la mercadería & & 6946,00 \\
\hline Fletes internos & & 1500,00 \\
\hline Seguro interno & $0,7 \%$ & 49,00 \\
\hline Certificaciones & & 11,00 \\
\hline Gastos aduaneros & & 450,00 \\
\hline Gastos fijos bancarios & & 500,00 \\
\hline Otros gastos & $1,0 \%$ & 0,00 \\
\hline TOTAL COSTOS DE EXPORTACIÓN & 9456,00 \\
\hline $\begin{array}{l}\text { Comisión despachante de } \\
\text { aduanas }\end{array}$ & $0,6 \%$ & 63,45 \\
\hline Gastos bancarios & $12,0 \%$ & 105,77 \\
\hline TOTAL GASTOS INDIRECTOS & $1,75 \%$ & 165,25 \\
\hline COSTO TOTAL & $1,5 \%$ & 587,29 \\
\hline Derechos de exportación & 10576,06 \\
\hline Reintegros a cobrar & & \\
\hline Impuesto a las ganancias & & \\
\hline VALOR FOB & & \\
\hline
\end{tabular}

Tabla 10: Costos de exportación 
Fuente: Ventanilla Única de Comercio Exterior. (VUCE) $)^{69}$

\begin{tabular}{|l|l|l|}
\hline COSTOS DE IMPORTACIÓN & $\%$ & USD \\
\hline Valor FOB & & 10576,00 \\
\hline Flete internacional & & 460,00 \\
\hline Seguro internacional & $0,5 \%$ & 52,88 \\
\hline VALOR CIF & & 11088,88 \\
\hline Arancel de importación & $0,0 \%$ & 0,00 \\
\hline IVA & $19,0 \%$ & 2106,89 \\
\hline Gastos aduaneros & & 650,00 \\
\hline Certificaciones & & 34,00 \\
\hline COSTOS DE IMPORTACIÓN & & 13879,77 \\
\hline
\end{tabular}

Tabla 11: Costos de importación.

Fuente: Tesis "Proyecto para la exportación de frutos secos" de la maestranda Gheraldine Mancilla.

Es importante resaltar que, en el costo total de la mercadería, el $38 \%$ corresponde a la compra de nueces de nogal, el $32 \%$ a las nueces de pecán y el $30 \%$ restante a los pistachos con cáscara. Estos porcentajes serán tenidos en cuenta al momento de establecer el precio de cada caja por especie.

\begin{tabular}{|l|r|r|}
\hline CONCEPTO & \multicolumn{1}{|c|}{ USD } & \multicolumn{1}{c|}{\begin{tabular}{c}
\multicolumn{1}{c|}{ PESOS } \\
COLOMBIANOS
\end{tabular}} \\
\hline Valor FOB & 10576,06 & $\$ 35.958 .604,00$ \\
\hline Valor CIF & 11088,88 & $\$ 37.702 .192,00$ \\
\hline Costo total 600 kilos mercadería importada & 13879,77 & $\$ 47.191 .218,00$ \\
\hline Fraccionamiento y empacado & 1200 & $\$ 4.080 .000,00$ \\
\hline $\begin{array}{l}\text { Costo total de de la mercadería empacada en unidades } \\
\text { de 100 gramos }\end{array}$ & 15079,77 & $\$ 51.271 .218,00$ \\
\hline
\end{tabular}

\footnotetext{
${ }^{69}$ Ventanilla Única de Comercio Exterior. (VUCE) Recuperado de: http://calculadora.vuce.gob.ar/\#!!
} 
Tabla 12: Costos de la mercadería.

Fuente: Cálculos propios

Tomando el costo total de USD 14879,77, USD 5.730,31 corresponden al costo de las nueces de nogal, USD 4.825 al costo de las nueces de pecán y USD 4.523 al costo de los pistachos.

\begin{tabular}{|l|l|l|}
\hline CÁLCULO DE PRECIO DE LAS NUECES DE NOGAL & USD & $\begin{array}{l}\text { PESOS } \\
\text { COLOMBIANOS }\end{array}$ \\
\hline $\begin{array}{l}\text { Costo de } 2.000 \text { unidades de mercadería importada, } \\
\text { fraccionada y empacada }\end{array}$ & 5730,31 & $\$ 19.483,954$ \\
\hline Costo por unidad de 100 gramos & 2,8 & $\$ 9.520,00$ \\
\hline Utilidad (40\%) & 1,12 & $\$ 3.808,00$ \\
\hline Precio por unidad & 3,92 & $\$ 13.328,00$ \\
\hline $\begin{array}{l}\text { Precio por caja de } 50 \text { unidades (100 gramos cada una) } \\
\text { de nueces de nogal }\end{array}$ & 196 & $\$ 666.400,00$ \\
\hline
\end{tabular}

Tabla 13: Cálculo de precios de las nueces de nogal.

Fuente: Cálculos propios

De acuerdo a lo anterior, tendríamos entonces 40 cajas de 50 unidades de 100 gramos cada una de nueces de nogal a un precio de USD 196 cada caja.

\begin{tabular}{|l|l|l|}
\hline CÁLCULO DE PRECIO DE LAS NUECES DE PECÁN & USD & $\begin{array}{l}\text { PESOS } \\
\text { COLOMBIANOS }\end{array}$ \\
\hline $\begin{array}{l}\text { Costo de } 2.000 \text { unidades de mercadería importada y } \\
\text { empacada }\end{array}$ & 4825 & $\$ 16.405 .000$ \\
\hline Costo por unidad de 100 gramos & 2,4 & $\$ 8.094,58$ \\
\hline Utilidad (90\%) & 2,16 & $\$ 7.344,00$ \\
\hline Precio por unidad & 4,56 & $\$ 15.504,00$ \\
\hline
\end{tabular}


Precio por caja de 50 unidades (100 gramos) de nueces de nogal

Tabla 14: Cálculo de precio de las nueces de pecán.

Fuente: Cálculos propios.

De acuerdo a lo anterior, tendríamos entonces 40 cajas de 50 unidades de 100 gramos cada una de nueces de pecán a un precio de USD 228 cada caja.

\begin{tabular}{|l|l|l|}
\hline CÁLCULO DE PRECIO DE LOS PISTACHOS & USD & $\begin{array}{l}\text { PESOS } \\
\text { COLOMBIANOS }\end{array}$ \\
\hline $\begin{array}{l}\text { Costo de 2.000 unidades de mercadería importada y } \\
\text { empacada }\end{array}$ & 4523 & $\$ 15.381 .365$ \\
\hline Costo por unidad de 100 gramos & 2,2 & $\$ 7.604,00$ \\
\hline Utilidad (65\%) & 1,43 & $\$ 4.862,00$ \\
\hline Precio por unidad & 3,63 & $\$ 12.342,00$ \\
\hline $\begin{array}{l}\text { Precio por caja de } 50 \text { unidades (100 gramos) de nueces } \\
\text { de nogal }\end{array}$ & 181,50 & $\$ 617.100,00$ \\
\hline
\end{tabular}

Tabla 15: Cálculo de precio de los pistachos.

Fuente: Cálculos propios.

De acuerdo a lo anterior, tendríamos entonces 40 cajas de 50 unidades de 100 gramos cada una de pistachos a un precio de USD 181,50 cada caja.

La estimación de los precios es coherente con la estrategia que permite ubicar un precio acorde a la calidad percibida del producto, ubicando la utilidad el $40 \%$ y el $90 \%$. 


\subsection{Política de distribución}

La función de distribución da valor añadido a la labor comercial de los productos y servicios de cara a los clientes, porque les proporciona tres utilidades clave: tiempo, lugar y posición ${ }^{70}$.

\subsubsection{Diseño del canal de distribución}

El diseño de distribución para Geven Frutos Secos comprende un canal largo, constituido así:

Esquema 6: Diseño del canal de distribución.

El producto llegará a nuestra base de operaciones logísticas en Cartagena, Colombia, proveniente desde Argentina.

Una vez aquí, la empresa elegida para las labores de fraccionamiento y empacado FRUTCOM SAS, procederá con la preparación de las 2.000 unidades de 100 gramos por especie, en cajas de los frutos secos para un total de 6.000 unidades listas para la venta; las mismas serán almacenadas para su posterior comercialización.

Después del primer embarque, la idea es continuar con la distribución de los productos a los mayoristas, para esto, el canal elegido es la Internet, desde donde podrán hacer sus pedidos de cajas con 50 unidades de cada producto, que luego serán distribuidos.

La idea inicial es que los clientes mayoristas correspondan a supermercados de cadena, cadenas de tiendas de productos naturales y cadenas de gimnasios con cafeterías.

\subsubsection{Características del website para la comercialización en Colombia}

${ }^{70}$ Alvarez, L. C (2016). Plan de marketing empresarial. (cc.3, pp.77) Madrid: Ediciones Paraninfo 
Se desarrollará un sitio web que tendrá dos funciones importantes, primero servirá de vitrina e información a los clientes, y segundo un e-commerce que les permite a los mayoristas hacer sus pedidos desde donde estén en Colombia, para luego distribuir la mercancía a través de una empresa especializada en logística.

El objetivo del website es ofrecer una experiencia de compra ágil e intuitiva, que le permita al cliente mayorista encontrar con facilidad las variedades de frutos secos y comprar de manera segura.

La jerarquía de contenidos en la plataforma de internet comprende:

- Productos: las variedades de frutos secos disponibles en sus distintas presentaciones, especificaciones y precio.

- Blog: espacio para publicar recetas, tips y noticias relacionadas con frutos secos.

- Nosotros: breve reseña sobre la empresa y lineamientos de la marca.

- Contáctanos: WhatsApp para dudas, e-mail.

\subsection{Políticas de comunicación}

La política de comunicación da a conocer las tres anteriores estrategias del Marketing Mix. El cliente debe conocer qué producto es, a qué precio está, y dónde lo puede adquirir. Es un proceso continuo en el que intervienen diversos elementos para obtener información, así como difundirla. ${ }^{71}$

El público meta de las comunicaciones de Geven Frutos Secos son hombres y mujeres colombianos desde los 18 años de edad, de nivel socioeconómico medio-alto y alto; personas activas, que practican deporte regularmente, acostumbran a preparar sus alimentos en casa o prefieren visitar restaurantes con opciones saludables, les interesa

\footnotetext{
71 Alvarez, L. C (2016). Plan de marketing empresarial. (cc.5, pp.103) Madrid: Ediciones Paraninfo
} 
mantenerse al día con noticias relacionadas a la alimentación, la salud y el deporte. Este grupo aún no conoce la marca, ya que es nueva en el mercado colombiano.

\subsubsection{Objetivo de comunicación}

El objetivo principal de comunicación es crear recordación de marca en los potenciales consumidores, que motive a la compra de los productos ofrecidos. Básicamente la idea es darse a conocer y fortalecer el brand equity de Geven Frutos Secos en Colombia.

\subsubsection{Estrategia de comunicación}

El mensaje estratégico de la marca va enfocado en resaltar el beneficio racional que genera el producto en el consumidor, vinculándolo con lo emocional.

Concepto de marca:

Es posible alimentarse bien sin renunciar al sabor.

Frases publicitarias:

El snack que te alimenta.

Tan rico y tan natural.

Más que un snack.

\subsubsection{Canales de comunicación}

Los canales de comunicación elegidos para la estrategia de Geven Frutos Secos son 100\% digitales, se llevarán a cabo campañas publicitarias en las siguientes plataformas:

- Google ADS

- Posicionamiento SEO

- Facebook e Instagram 
Paralelamente a lo anterior, Geven Frutos Secos será partícipe de ferias gastronómicas que se realicen en Colombia donde haya potencial de dar a conocer el producto, tales como Sabor Barranquilla en Barranquilla, Alimentec y Alimentarte Food Festival en Bogotá.

\subsection{Conclusiones}

Las cuatro variables del Marketing Mix sobre las que se asientan las principales estrategias de Marketing Internacional a seguir por parte de Geven Frutos Secos, permitirán alcanzar los objetivos de Marketing propuestos al inicio de este capítulo.

La incursión de una nueva marca a un nuevo mercado internacional conlleva una serie de riesgos capaces de minimizarse a través de un correcto planeamiento de marketing.

Los costos de las estrategias expuestas en este capítulo serán detallados en el capítulo siguiente. 


\section{VIABILIDAD ECONÓMICA Y FINANCIERA DEL PROYECTO}

La delimitación y puesta en práctica de las distintas actuaciones del marketing requiere cuantificar los recursos necesarios para su ejecución. El análisis del entorno interno de la empresa ofrece claridad sobre las posibilidades y limitaciones económicas de la misma, de modo que la acción presupuestaria consiste en determinar qué parte de ese presupuesto disponible se dedicará a cada una de las acciones del marketing programadas. ${ }^{72}$

A continuación, se presenta una tabla con el resumen de la inversión total inicial necesaria para llevar a cabo este proyecto:

\begin{tabular}{|l|l|l|}
\hline \multirow{4}{*}{ CONCEPTO } & ITEMS & $\begin{array}{l}\text { INVERSIÓN EN } \\
\text { USD }\end{array}$ \\
\hline \multirow{4}{*}{$\begin{array}{l}\text { Trámites } \\
\text { administrativos }\end{array}$} & Constitución de la Sociedad Comercial & 50 \\
\cline { 2 - 3 } & Inscripción ante la AFIP como PYME & 0 \\
\cline { 2 - 3 } & Inscripción como exportador en Argentina & 0 \\
\cline { 2 - 3 } & Inscripción como importador en Argentina & 0 \\
\hline \multirow{4}{*}{ Mercadería } & Costo de la mercadería & 6946 \\
\hline \multirow{5}{*}{ Comunicación } & $\begin{array}{l}\text { Costos de exportación e importación del } \\
\text { producto }\end{array}$ & 6934 \\
\cline { 2 - 3 } & Empacamiento y fraccionado & 1200 \\
\hline & Creación del website & 500 \\
\cline { 2 - 3 } & Publicidad en Google ADS & 200 \\
\cline { 2 - 3 } & Posicionamiento SEO de la página web & 250 \\
\cline { 2 - 3 } & Publicidad en Facebook e Instagram & 120 \\
\hline
\end{tabular}

${ }^{72}$ García, M. S (2014) Plan e informes de marketing internacional. España: IC Editorial 
Tabla 16: Presupuesto de la inversión inicial.

Fuente: Cálculos propios.

Conforme a los datos anteriores, la inversión inicial para comenzar el proyecto es de USD 16.200

A continuación, una tabla con el flujo de caja proyectado a 5 años:

\begin{tabular}{|l|l|l|l|l|l|l|l|}
\hline \multicolumn{6}{|l|}{ Geven Frutos secos } \\
\hline Flujo de caja proyectado a 60 meses \\
\hline Concepto & Mes 0 & Mes 1 & Mes 12 & Mes 24 & Mes 36 & Mes 48 & Mes 60 \\
\hline INGRESOS & & & & & & & \\
\hline Inversión & $16.200,00$ & & & & & & \\
\hline Ventas & & $7.640,42$ & $10.505,57$ & $14.325,78$ & $18.145,99$ & $19.101,04$ & $19.101,04$ \\
\hline Total ingresos & $16.200,00$ & $7.640,42$ & $10.505,57$ & $14.325,78$ & $18.145,99$ & $19.101,04$ & $19.101,04$ \\
\hline EGRESOS & & & & & & & \\
\hline Preliminares & $1.120,00$ & & & & & & \\
\hline Compra de & & & & & & & \\
producto & $15.079,77$ & & $22.619,66$ & $30.159,54$ & $37.699,43$ & $37.699,43$ & \\
\hline Organizacionales & & $1.163,33$ & $1.163,33$ & $1.745,00$ & $3.490,00$ & $3.490,00$ & $3.490,00$ \\
\hline Distribución & & 333,33 & 458,33 & 625,00 & 791,67 & 833,33 & 833,33 \\
\hline Gastos de ventas & & 191,01 & 262,64 & 358,14 & 453,65 & 477,53 & 477,53 \\
\hline Total egresos & $16.199,77$ & $1.687,68$ & $24.503,96$ & $32.887,68$ & $42.434,74$ & $42.500,28$ & $4.800,86$ \\
\hline Resultado & 0,23 & $5.952,74$ & $-13.998,39$ & $-18.561,90$ & $-24.288,75$ & $-23.399,24$ & $14.300,18$ \\
\hline $\begin{array}{l}\text { Acumulado de } \\
\text { caja }\end{array}$ & $\underline{0.23}$ & $\underline{5.952,97}$ & $\underline{8.275,48}$ & $\underline{22.107,63}$ & $\underline{27.536,67}$ & $\underline{48.341,16}$ & $\underline{106.845,08}$ \\
\hline
\end{tabular}

Tabla 17: Flujo de caja proyectado a 5 años.

Fuente: cálculos propios.

\subsection{Conclusiones}


Los datos expuestos por las proyecciones y el análisis financiero de Geven Frutos Secos nos arrojó de resultados un TIR de 62,13\% y un VAN de 15.056 USD nos muestra que el proyecto es viable y está dado para operar.

En el flujo de caja se puede comprobar que la inversión inicial de 16.200 USD se ha recuperado en el mes 21 , pues la compra de este mes ya deja un remanente que cubre este valor.

Se obtuvieron los datos de los costos de la exportación, información suministrada por la tesis de la maestranda Gheraldine Mancilla, que ayudó a fijar el precio del producto y realizar decisión de la viabilidad del proyecto. 


\section{CONCLUSIONES GENERALES}

Este proyecto recopiló toda la información exploratoria para llevar a cabo un plan estratégico de marketing internacional para la comercializadora Geven Frutos Secos, empresa que nace en Argentina, pero inicia sus labores comerciales en Colombia.

Esta tesis es complementaria con el "Proyecto para la exportación de frutos secos", desarrollado por la maestranda Gheraldine Mancilla.

Para analizar la posibilidad y viabilidad de esta comercializadora, se llevó a cabo una serie de pasos que nos fueron permitiendo llegar a la concepción de esta idea que espero materializar en un futuro cercano.

Primero, se analizaron las características del mercado destino, situación a nivel nacional y mundial del producto y su consumo. Todo esto permitió evidenciar la oportunidad de negocio y llegar a las conclusiones expresada a continuación:

Con respecto al incremento del consumo de alimentos saludables que se viene dando en el mundo, da pie al potencial de la demanda permitiendo nuevas propuestas de negocio para este tipo de mercado.

Para tener una visión más precisa y favorable de comercializar frutos secos en Colombia, se puso en práctica el análisis FODA el cual nos arrojó datos importantes del mercado y la viabilidad del mismo.

Se estableció, después de un análisis de la segmentación en Colombia, que- a partir de los 18 años de edad- las personas tienden a cuidarse más y ser conscientes de lo que comen; también arrojó que el nivel socio económico de clientes es medio-alto y alto, en este segmento las personas se preocupan más por los alimentos sanos y nutritivos, el target son personas muy activas que se ejercitan y personas con tiempos limitados, tipo ejecutivo. 
Los objetivos expuestos para este plan estratégico de marketing internacional, llevan consigo las estrategias del marketing, pilar fundamental para una empresa que está iniciando un proceso de internacionalización las cuales fueron, la funcional ya que combina los diferentes medios, el marketing Mix.

El Producto: son tres variedades escogidas inicialmente, nuez de nogal, nuez de pecán y los pistachos, empacados en un diseño novedoso de 100 gramos cada presentación en cajas de 50 unidades que serán vendidas a mayoristas.

El precio será fijado por el valor percibido del cliente, el producto se va a diferenciar a través de su calidad, al ser importado desde Argentina y por el diseño de su empaque.

La comunicación que va a utilizar Geven Frutos Secos es netamente digital, a través de website, redes sociales y Google Ads, donde los mayoristas podrán hacer sus pedidos por medio del e-commerce, y que sirva también como vitrina para los nuevos clientes.

Los datos arrojados por las proyecciones y análisis financiero nos arrojaron un TIR de $62,13 \%$ y un VAN de 15.056 USD, que nos muestra que el proyecto es viable, está dado para operar, teniendo en sus tres primeros años un saldo negativo, lo que es normal para una empresa que inicia operaciones e incursiona en el mercado internacional.

Considerando todos los puntos expuestos en este trabajo de tesis, la comercializadora Geven Frutos Secos constituye una idea de negocio con grandes oportunidades y rentabilidad para el mercado destino, ya que en Colombia no se cultivan frutos secos y la demanda de los consumidores apunta hacia opciones saludables. 
9. ÍNDICE BIBLIOGRÁFICO

\subsection{Bibliografía formal- libros}

Alvarez, L. C (2016). Plan de marketing empresarial. Madrid: Ediciones Paraninfo

Carpintero, L. (2014) Plan e informes de marketing internacional. España: Ediciones Paraninfo S.A.

García, M. S (2014) Plan e informes de marketing internacional. España: IC Editorial

Hernández, C. (2017) Manual. Fundamentos del plan de marketing en internet. Madrid: Editorial CEP

Hoyos, R. (2013) Plan de marketing: diseño, implementación y control. Bogotá: Ecoe Ediciones

Lambin, J. J. (1995) Marketing Estratégico. Madrid: Mc Graw Hill

Kotler, Philip y Keller Lane k. (2006) Dirección de Marketing. Versión 12. Mexico. Pearson educación.

9.2. Fuentes de Internet

ALADI. Acuerdo de Complementación Económica MERCOSUR. Recuperado de: http://www2.aladi.org/biblioteca/Publicaciones/ALADI/Acuerdos/ACE/ES/ACE72/ACE 072.pdf 
Alimentos argentinos. Recuperado de:

http://www.alimentosargentinos.gob.ar/HomeAlimentos/Nutricion/fichaspdf/Ficha 54

Frutos Secos.pdf

Asociación Española de personas con Alergias a Alimentos y Látex (AEPNAA). Recuperado de: https://www.aepnaa.org/ver/frutos-secos

Banco Mundial. Recuperado de: https://www.bancomundial.org/es/country/argentina/overview

Centro Virtual de Negocio (CVN). Recuperado de:

Código Alimentario Argentino, Capítulo XI. Recuperado

de https://www.argentina.gob.ar/anmat/codigoalimentario

Consejo Internacional de Frutos Secos (INC). Recuperado de:

https://www.nutfruit.org/consumers

Departamento Administrativo Nacional de estadísticas. (DANE) Recuperado de: https://id.presidencia.gov.co/Paginas/prensa/2019/190704-Poblacion-de-Colombiaes-de-48-2-millones-habitantes-segun-DANE.aspx

Departamento Nacional de Planeación (DNP). Recuperado de: https://www.dnp.gov.co/DNPN/Paginas/default.aspx

En base a distintos sitios webs de comercializadoras y supermercados. Recuperado de: https://www.jumbo.com.ar/frutas-y-verduras, https://insualimentos.com/, https://www.exito.com/mercado/frutas-y-verduras/frutas

https://www.cvn.com.co/wp-content/uploads/2018/08/4-Bebidas-alcoholicas-frutos-secos1.pdf

Instituto Nacional de Estadísticas. (INDEC) Recuperado de: https://opex.indec.gov.ar/index.php?pagina=mapa dinamico

Instituto Nacional de Vías. Recuperado de: https://www.invias.gov.co/ 
Instituto Nacional de Vigilancia de Medicamentos y Alimentos. INVIMA. Recuperado de: https://www.invima.gov.co/documents/20143/1402493/26.+Instructivo+para+la+Vigila $\underline{\text { ncia }+ \text { del+Rotulado+de+Alimentos } \% 2 C+\text { Bebidas }+y+s u s+M a t e r i a s+P r i m a s . p d f}$

Ministerio de Agricultura y Desarrollo Rural. Recuperado de: https://www.agronet.gov.co/Paginas/inicio.aspx

Ministerio de Agricultura, Gobierno de Chile (ODEPA). Recuperado de: https://www.odepa.gob.cl/wpcontent/uploads/2017/12/FrutosSecosSustantabilidad2017.pdf

Ministerio de Desarrollo Productivo. Registrarse como PYME. Recuperado de: https://www.argentina.gob.ar/produccion/registrarse-como-pyme

Nielsen Company. Recuperado de: https://www.nielsen.com/co/es/insights/article/2018/4-decada-10-colombianos-estan-cambiando-a-la-version-saludable-de-su-productopreferido/

Organización de las Naciones Unidas para la Alimentación y la Agricultura. FAO. Recuperado de: http://www.fao.org/3/a-v8929e.pdf

Organización Mundial de la Salud. (OMS). Recuperado de: https://www.who.int/es

PROCOLOMBIA. Exportaciones Turismo Inversión Marca País. Recuperado de: https://tlceeuu.procolombia.co/oportunidades-por-sector/agroindustria/pasabocas-o-snacks

Resolución 683 de 2012. Ministerio de Salud Colombia. Recuperado de: https://www.minsalud.gov.co/sites/rid/Lists/BibliotecaDigital/RIDE/DE/DIJ/resolucion0683-de-2012.pdf

Ventanilla Única de Comercio Exterior. (VUCE) Recuperado de: http://calculadora.vuce.gob.ar/\#!/ 
"Declaro bajo juramento que esta tesis fue elaborada por mí, que no utilicé ningún otro material que no haya dado a conocer en las referencias y que no utilicé frases o párrafos de otros autores y que este trabajo de tesis nunca ha sido presentado ante un comité de evaluación de tesis y que no transgrede derechos de terceros."

Steven Cerpa Pinto.

Buenos Aires, 9 de marzo de 2020. 